

\title{
The economic impact of a deep decarbonisation pathway for China: a hybrid model analysis through bottom-up and top-down linking
}

Xin Su, Frédéric Ghersi, Fei Teng, Gaëlle Le Treut, Meicong Liang

\section{- To cite this version:}

Xin Su, Frédéric Ghersi, Fei Teng, Gaëlle Le Treut, Meicong Liang. The economic impact of a deep decarbonisation pathway for China: a hybrid model analysis through bottom-up and top-down linking. 2021. hal-03487333

\section{HAL Id: hal-03487333 \\ https://hal-enpc.archives-ouvertes.fr/hal-03487333}

Preprint submitted on 17 Dec 2021

HAL is a multi-disciplinary open access archive for the deposit and dissemination of scientific research documents, whether they are published or not. The documents may come from teaching and research institutions in France or abroad, or from public or private research centers.
L'archive ouverte pluridisciplinaire HAL, est destinée au dépôt et à la diffusion de documents scientifiques de niveau recherche, publiés ou non, émanant des établissements d'enseignement et de recherche français ou étrangers, des laboratoires publics ou privés. 


\section{The economic impact of a deep}

\section{decarbonisation pathway for China: a hybrid model analysis through bottom-up and top- down linking}

Xin Su ${ }^{a}$, Frédéric Ghersi ${ }^{b, c}$, Fei Teng ${ }^{a, *}$, Gaëlle Le Treut ${ }^{b}$, Meicong Liang ${ }^{a}$

${ }^{a}$ Institute of Energy, Environment and Economy, Tsinghua University, Beijing.

${ }^{b}$ CIRED - Centre International de Recherche sur l'Environnement et le Développement, 45 bis, avenue de la Belle Gabrielle, 94736, Nogent-sur-Marne CEDEX, France.

${ }^{c}$ CNRS - Centre National de la Recherche Scientifique, 3 rue Michel-Ange, 75794, Paris cedex 16, France.

* Corresponding author: Institute of Energy, Environment and Economy, Tsinghua University, Beijing. E-mail: tengfei@tsinghua.edu.cn

\section{Abstract}

The development of mid-century low-emission development strategies is critical to guiding national actions on long-term mitigation. One of the key concerns in developing mitigation strategies is the cost of low-carbon transition. In this study, we estimate the macroeconomic cost of a deep decarbonisation pathway for China, by integrating an energy-systems optimization model with an economic model through hard linking. Our results indicate that deep decarbonisation increases the energy expenses of Chinese households in the mid-run due to the higher cost of electricity. However, firms will benefit from moderate decarbonization through a reduction in coal and oil consumption. Energy-efficiency improvements lead to a reduction in firms' total energy costs, partially compensating the crowdingout effect of low-carbon investments on general productive capital. Our mitigation scenario has therefore a small macroeconomic cost compared to business as usual, equal to a lag in growth of less than one year in 2050 . 


\section{Keywords}

Hybrid energy-economy model; China; deep decarbonisation pathways; mitigation

\section{Introduction}

The Paris Agreement invites Parties to submit mid-century low-emission development strategies before the end of 2020 (Waisman et al., 2019; Bataille et al., 2020), to inform the evolution of their Nationally Determined Contributions (NDC), the 'global stocktake' process and the compatibility with long-term temperature goals. As of mid-October 2020, only nineteen countries had submitted their mid-century strategies, with most countries still working on drafting and consulting, including China. ${ }^{1}$ The cost of transforming energy systems is a top concern for policymakers setting emissions reduction targets at the national and sectoral level in the context of mid-century mitigation strategies (Fujimori et al., 2019; Jacobsson and Lauber, 2006; Rogelj et al., 2015). Consequently, the key policy questions are how this decarbonization process interacts with economic development and what macroeconomic implications result from this shift (Intergovernmental Panel on Climate Change and Edenhofer, 2014).

Both technology-rich models of energy systems (so-called bottom-up or BU models) and macroeconomic models (so-called top-down or TD models) have been used to analyse the economic implication of mitigation policies, especially the cost of low-carbon transformation. BU models are characterised by detailed information on technologies. They are attractive to policymakers by offering in-depth analysis of energy transformation roadmaps, the associated investment and fuel costs. However, as partial equilibrium models, BU models are not capable of capturing the impact on important non-energy sectors, and also vital policy-relevant socio-economic indicators, such as the impact on growth and job creation. On the other hand, the general equilibrium structure of most TD

\footnotetext{
${ }^{1}$ See https://unfccc.int/process/the-paris-agreement/long-term-strategies.
} 
models allows for a thorough economic analysis on critical socio-economic indicators, but lacks technical detail to guide implementation, especially at sectoral level.

Keeping global temperature rise well below 2 degrees will require significant investments in lowcarbon abatement technology, as well as de-investment from fossil fuel-based technology. Disruptive changes in investment trends might have a big impact on other sectors in the economy. Due to the interaction between energy and other parts of the economy, linking or integrating the two kinds of models (BU and TD) is being considered as a way of guiding policymaking in a more holistic manner (Hourcade et al., 2006). The term "hybrid models" refers to models that link TD and BU models. There are various model linking methodologies and approaches, but we adopt Wene's (1996) definition of soft-linking as information exchange with human intervention versus "hard-linking" as a computercontrolled, automated exchange.

The deep decarbonisation of China's energy system has attracted intensive research attention from both the bottom-up and top-down modelling communities. However, very few studies use hybrid models to explore the macroeconomic implication of deep decarbonisation pathways in China. Dai et al. (2016a) combined the TIAM BU model to a world TD CGE model and explored both a baseline and a carbon tax scenario, but their focus was methodological: they compared the tax incidence on emissions in their TD, BU and linked frameworks rather than the baseline and carbon-tax scenarios. Existing hybrid model studies have the following shortcomings: Firstly, TD models mostly use inputoutput tables as the main data base, while BU models mostly use energy balance sheets. Since there are often data differences between input-output tables and energy balance sheets, existing studies are not built on a consistent data base. Secondly, most existing hybrid models assume uniform energy prices and do not take into account the sectoral heterogeneity of energy prices. Thirdly, key variables such as energy price are not adjusted to reflect the different definition between TD and BU models.

In this paper, we combine a compact TD model KLEM-CHN with a BU model China-MAPLE through a hard-linking strategy, which allows us to explore the macroeconomic impact of a deep decarbonisation 
pathway for China in the medium run. Our TD modelling rests on a hybrid energy/economy dataset that significantly improves the linking of BU and TD models through the consistency of calibration data (Hourcade et al., 2006). Our hybrid approach therefore reconciles BU and TD not only by linking existing models but also by building an original hybrid database combining national accounting and energy balance data. Using the consistent hybrid database, we developed a hybrid model to analyze the economic effects of deep decarbonization in China. Based on our analysis, the economic cost of moderate mitigation pathways is manageable, equal to a growth lag of less than one year by 2050 .

Our paper is organized as follows. In section 2, we review the literature on both Chinese mitigation pathways and hybrid BU/TD modelling. In section 3, we introduce our TD and BU models, as well as how we integrate those two models through a hard linking strategy. We then present the scenario design and discuss scenario results in section 4 . We conclude in section 5.

\section{Literature review}

As the largest greenhouse gas emitter and developing country in the world, China faces many socioeconomic challenges alongside its low-carbon transformation. This topic received intensive research interest from TD modellers using CGE as the primary tool of analysis. Past studies have examined the impact of market-based policies, such as carbon tax and emissions trading schemes. Other studies assessed the economic implication of regulation policies, such as renewable portfolio standards. For instance, Dai et al. (2016b) analysed the cost of achieving a specific reduction target by imposing a carbon tax in China, and stressed that a moderate carbon tax is suitable for $\mathrm{CO}_{2}$ mitigation while a high carbon cost is significantly harmful to the economy and welfare. Liu and Lu (2015) pointed out that carbon-revenue recycling schemes have a significant influence on the policy effects and policy impact on the economy. Dai et al. (2018) discussed the impact of aligning renewable energy targets with a carbon emissions trading system. These researches based on CGE models provide important insights into the implementation of pricing policies in the form of either a carbon tax or a cap-and-trade system. 
However, China also adopts many non-market policies and measures in the energy transition, especially regulations such as fuel-efficiency standards, power-generation expansion plans, and pollutant emission standards. It is essential to apply modelling tools to analyse the socioeconomic impact of those non-market policies and measures. Some studies on China tried to address this requirement by improving the energy-system details in CGE models. Disaggregation of the energy sectors is the first choice in that direction (Dai et al., 2016a, 2018; Zhang et al., 2013). Adapting other exogenous parameters and modules can also help, for instance, Mu et al. (2018) modelled the shares of renewable energies targeted by the Chinese government through disaggregation of the electricity sector into several subsectors and the adjustment of exogenous mark-up factors for these subsectors. Duan et al. (2014) employed a logistic sub-model in their CGE model to simulate the diffusion process of renewable energy. However, all these efforts are limited to selected sectors and not detailed enough to consider economy-wide non-market policies. Another shortcoming of CGE models is that their parameters are generally calibrated on historical data that does not cover transformations as dramatic as those of the low-carbon transition. This often leads CGE models to estimate higher low-carbon transition costs than BU models do (Fujimori et al., 2019).

A hybrid approach combining BU and TD has the great advantage to incorporate energy-systems information into economic models and represent important feedbacks between models. Although hybrid approaches have been applied to many country studies, very few studies concern China. Chen (2005) builds a MARKAL-MACRO model of China to analyse the GDP losses of different $\mathrm{CO}_{2}$ reduction rates. Dai et al. (2016a) implement the global BU model TIAM and the global TD model AIM both separately and linked with a focus on China.

A hybrid framework can be either hard-linked, soft-linked, or fully integrated (Helgesen and Tomasgard, 2018). Soft-linking and hard-linking approaches build upon pre-existing TD and BU models, and provide more transparency and flexibility. They have been applied to low-carbon transition analysis all over the world (Anderson et al., 2011; Fortes et al., 2013; Fujimori et al., 2019; Krook-Riekkola et al., 2017; 
Soummane et al., 2019; Wu et al., 2019). However, they may leave unresolved some inconsistencies between the two linked models. The fully integrated approaches solve the inconsistency problem (Abrell and Rausch, 2016; European Environment Agency, 2013; Proenca and Aubyn, 2009; Rausch and Mowers, 2014). But the integration framework needs to address the significant challenge of presenting detailed technologies in an economy-wide framework, which limits its application in empirical studies. Thus, a hard-linking or soft-linking hybrid approach is a natural start to combine the technological richness of BD models with the economic detail of TD models (Fujimori et al., 2019; Helgesen and Tomasgard, 2018).

Therefore, to understand the socio-economic challenges faced by China in its low-carbon transition process, we present a hybrid hard-linking framework combining an economy-wide model KLEM-CHN and a BU model China-MAPLE.

Compared to the previous hybrid modelling studies, this study has three methodological contributions. Compared to Chen (2005), our methodological contribution lies in the extension beyond the aggregate 3-factor production function of MACRO to a CGE setting, albeit aggregated. It also lies in the attention we give to reconcile the TD calibration data of KLEM-CHN with the BU data of China-MAPLE. In that regard, our 'hybrid' calibration process improves on the uniform energy price assumption of Dai et al. (2016a, Appendix A.7) by considering agent-specific pricing of energy goods (see Section 3.4 and Appendix C), which leads to significant statistical adjustments of economic flows, i.e. of modelling results (Combet et al., 2014). Our third methodological contribution is to extend model linking to information on the cost of energy supply and suggest a data adjustment method to ensure consistency between TD and BU models (see Section 3.4 and Appendix E), thereby investigating one of the research frontiers highlighted by Dai et al (2016a). These methodological improvements serve our ultimate purpose of producing an original applied contribution on the deep decarbonisation of China. 


\section{Method}

We model energy-economy outlooks of the Chinese economy by way of a hybrid modelling architecture that combines the strengths of the BU, 'technology-rich' China-MAPLE model of Chinese energy systems and the TD, economy-wide KLEM-CHN model of China. Our first step is to build a consistent hybrid dataset reconciling input-output tables and energy balance sheets. Then, we develop a TD model called KLEM-CHN, and calibrate it using the hybrid dataset. The third step is to link our TD model and BU model using a hard linking strategy. Finally, we suggest a method for ensuring consistency between TD and BU models during data iteration.

\subsection{Construction of a consistent hybrid dataset}

Upstream data consistency efforts consisted in the construction of an original hybrid dataset reconciling Chinese national accounting, energy balance and energy price statistics, on which to calibrate KLEM-CHN (see Appendix C). We conducted the process on a 42-sector disaggregation of the 2010 Chinese economy (National Statistics Bureau, 2011) with additional information from a 135sector 2012 disaggregation (National Statistics Bureau, 2015). It revealed significant inconsistencies between the energy expenses of national accounts and the energy balance and price statistics for major energy consuming sectors. Correction of such discrepancies allowed calibrating KLEM on a hybrid dataset consistent with the energy calibration data of MAPLE, thus significantly improving the relevance of our coupling endeavour. Importantly, the procedure extends to the original elicitation of agent-specific margins bridging the gap between the average supply price of energy plus net taxes, and the specific average consumer prices observed for each aggregate agent of KLEM-CHN: non-energy firms, energy firms, households and foreign importers (see Appendix C). 


\subsection{The BU and TD models}

The BU model China-MAPLE is an energy-system optimization model based on The Integrated MARKAL-EFOM System (TIMES) model generator (Loulou et al., 2016). China-MAPLE(Wang et al., 2017; Yang and Teng, 2017; Yang and Teng, 2018; Yang et al., 2017; Yang et al., 2018) portrays the entire energy system of China with a detailed description of thousands of technologies in energy supply, process, conversion and end-use sectors. An overview of China-MAPLE is provided in Appendix A. For more detailed information please refer to our previous works.

The TD model KLEM-CHN is designed to build macroeconomic outlooks under constraint of exogenous energy flows and prices trajectories informed by BU modelling, on both international and domestic markets. KLEM (for Capital, Labour, Energy and Materials) differentiates two sectors of economic activity: energy sector and non-energy sector in the rest of the economy. In this paper, we build the KLEM-CHN model within the framework of KLEM. Compared to the original KLEM framework (Soummane et al., 2019), KLEM-CHN develops more standard macroeconomics at longer horizons in larger time steps, and couples to the China-MAPLE model of the TIMES family through an iterative process of data exchange to convergence of both numerical systems. In such a framework, the benefit of KLEM is in comparison to the aggregate MACRO option of top-down coupling to TIMES (Manne, 1977; Chen, 2005; Remme and Blesl, 2006; Chen et al., 2007). ${ }^{2}$ Appendix B reports the technical details of KLEM-CHN.

\footnotetext{
${ }^{2}$ Compared to MACRO, KLEM covers international trade and input-output loops, although at a level of aggregation that forbids the explicit modelling of the influence of shifting sectoral contributions to non-energy activity. We postpone to further publication analyses based on coupling China-MAPLE to a multisector generalization of KLEM.
} 


\subsection{Coupling China-MAPLE to KLEM-CHN}

We couple China-MAPLE to KLEM-CHN by the iterative exchange of modelling results up to convergence (see Table 1 for the information exchanged between the two models). At the beginning of the iterative process, we run China-MAPLE on any exogenous energy demand trajectories to project the Chinese energy system in 5-year steps from its 2010 calibration year up to 2050 . We then process China-MAPLE outputs (or assumptions on international energy prices) into a series of energy flows, prices and costs trajectories to define inputs to KLEM-CHN. We run KLEM-CHN under constraint of this energy-system data to compute the GDP and non-energy output trajectories compatible with it and feed these trajectories back into China-MAPLE to run the latter model again (Figure 1). We iterate the process until either dataset varies less than a given tolerance threshold between one iteration and the next. The resulting China-MAPLE and KLEM-CHN outputs provide a consistent, highly detailed picture of the Chinese energy system embedded into the broader Chinese economy at activity levels that take account of feedback loops between energy, non-energy and primary factors supply, demand and relative prices. 
Figure $1 \quad$ Model coupling architecture

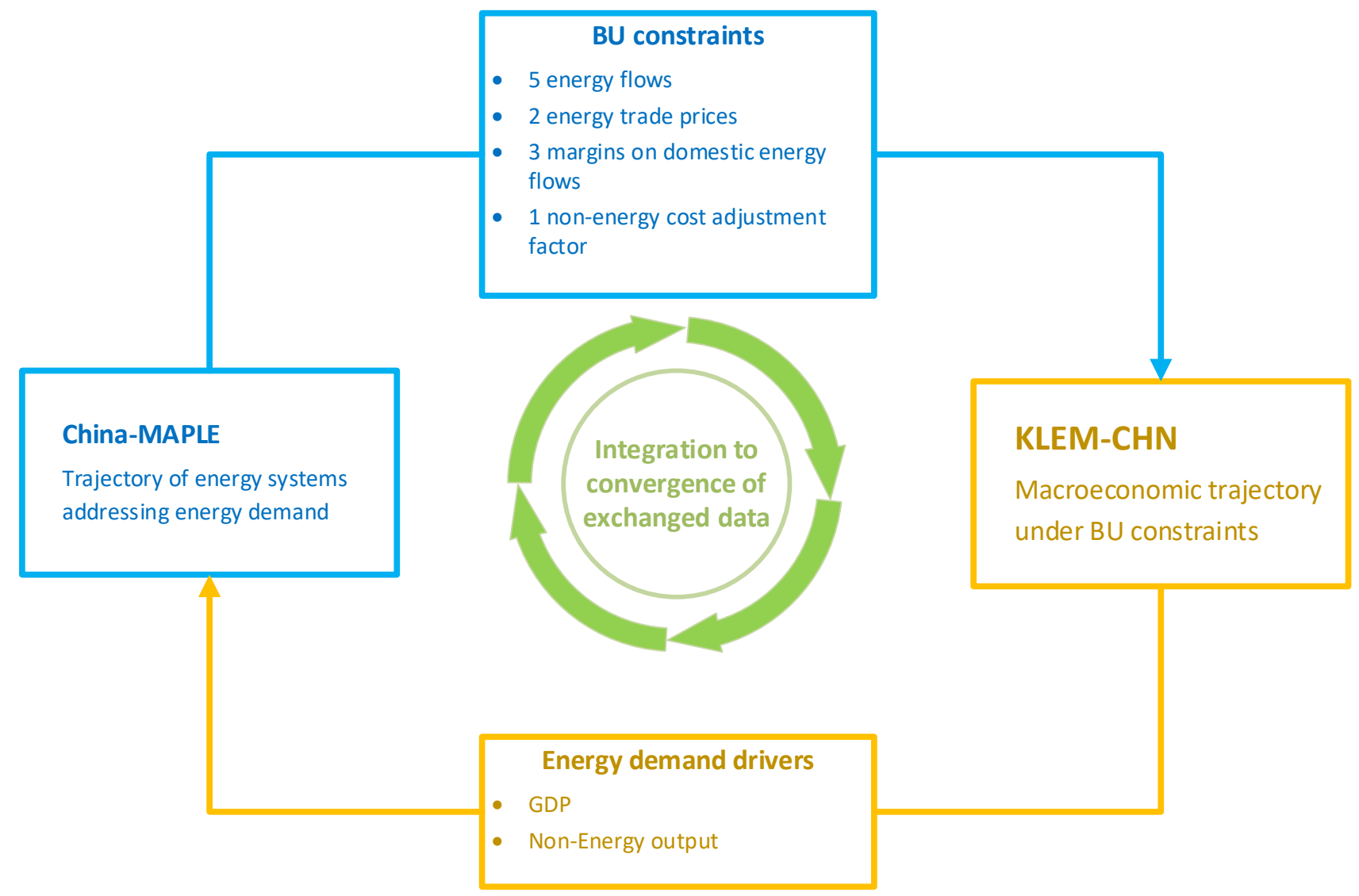




\begin{tabular}{|c|c|}
\hline Results from China-MAPLE & Influenced variables in KLEM \\
\hline $\begin{array}{l}\text { Energy consumption in energy sectors } \\
\text { (Power, Heating, Coking, Refinery sectors) }\end{array}$ & Energy Inputs to transformation by energy firms \\
\hline $\begin{array}{l}\text { Marginal costs of primary energy and } \\
\text { levelized costs of secondary energy }\end{array}$ & Price of Inputs to transformation by energy firms \\
\hline $\begin{array}{l}\text { Energy consumption in Industry and freight } \\
\text { transportation and commercial buildings }\end{array}$ & Final energy consumptions of non-energy firms \\
\hline $\begin{array}{l}\text { Marginal costs of primary energy and } \\
\text { levelized costs of secondary energy }\end{array}$ & Price of final energy consumptions of non-energy firms \\
\hline $\begin{array}{l}\text { Energy consumption in residential buildings } \\
\text { and passengers transportation }\end{array}$ & Final energy consumptions of households \\
\hline $\begin{array}{l}\text { Marginal costs of primary energy and } \\
\text { levelized costs of secondary energy }\end{array}$ & Price of final energy consumptions of households \\
\hline Net energy imports & Energy imports \\
\hline Marginal costs of energy imported & Price of energy imported \\
\hline Net energy exports & Energy exports \\
\hline $\begin{array}{l}\text { Marginal costs of primary energy and } \\
\text { levelized costs of secondary energy }\end{array}$ & Price of energy exported \\
\hline Results from KLEM & Influenced variables in China-MAPLE \\
\hline \multirow[t]{3}{*}{ Real non-energy output } & $\begin{array}{l}\text { Industry products demand including iron, steel, cement, } \\
\text { lime, brick, glass, ammonia, ethylene, fertilizer, copper, } \\
\text { aluminium, zinc, paper, clothing, other ferrous metals, } \\
\text { other metals, other chemicals. }\end{array}$ \\
\hline & $\begin{array}{l}\text { Heating, water heating, cooking, lighting, air-conditioning } \\
\text { and other equipment services in commercial buildings }\end{array}$ \\
\hline & Freight transportation services demand \\
\hline \multirow[t]{3}{*}{ Real GDP } & Passenger transportation services demand \\
\hline & $\begin{array}{l}\text { Heating, water heating, cooking, lighting, air-conditioning } \\
\text { and other equipment services in rural residential buildings }\end{array}$ \\
\hline & $\begin{array}{l}\text { Heating, water heating, cooking, lighting, air-conditioning } \\
\text { and other equipment services in urban residential buildings }\end{array}$ \\
\hline
\end{tabular}

Our methodological contribution does not lie in this iterative procedure-which Jorgenson proposed more than 40 years ago in our field (Hoffman and Jorgenson, 1977). It rather lies in upstream data consistency efforts as well as in original data processing to transform China-MAPLE information on any outlook scenario into information compatible with the input-output framework of KLEM-CHN. 


\subsection{Adjustment of energy flows and prices}

In both BU and TD models, energy prices and consumption are key variables. However, they cannot be exchanged directly since BU and TD models have different definitions. As an example, in the BU model, energy prices are defined as the marginal cost of energy production rather than the market price defined in the TD model. As a result, those variables must be adjusted before they can be exchanged during iteration. Our contribution is to suggest a method for adjusting the coupling variables and improving consistency between the TD and BU models, which is often overlooked in existing studies of model coupling.

Processing China-MAPLE results into formats compatible with KLEM-CHN is straightforward enough for energy flows after accounting for the same methodological discrepancies between energy balance and national accounting statistics that we corrected when building our hybrid 2010 database. These regard the decentralised generation of electricity, the geographical versus administrative take on national perimeters, especially affecting the recorded transport fuel consumptions or expenses (the question of international bunkers), and the aggregation of all transport-related consumptions into one single end-use versus their distribution across all activity branches, including transport services, and households. After treatment of these discrepancies, we aggregate China-MAPLE results into 5 out of the 6 trajectories of energy flows considered in KLEM-CHN: energy imports, energy 'consumptions' (transformations) by the energy supply sector, final energy consumptions by the non-energy sector and by households, and energy exports. The sixth trajectory, that of the output of the energy sector, flows from market balance on the five former ones (see KLEM Equations 14 and 15, Appendix C and Appendix E).

Processing China-MAPLE results into trends of energy costs or prices applicable to KLEM-CHN is more challenging. One important point to consider is that China-MAPLE models energy costs and not market prices-with the exception of exogenous international prices of tradable resources. As a linear 
programming model, China-MAPLE systematically reveals the marginal costs of supply of all energy carriers as the dual variables of the supply constraint to the optimisation. These marginal costs reflect the supply curves of primary energy well, but not those of secondary energy because of the determinant impact of scenario constraints on supply, which distorts implicit supply curves. ${ }^{3}$ We therefore rather compute the average levelised cost of secondary energies as a proxy of their production costs. We then compute averages of marginal or levelised costs weighted by supply shares to produce aggregate 'price' trajectories for the three domestic uses of the energy good in KLEM-CHN (see Appendix E).

A second point to consider is that China-MAPLE, as a partial equilibrium model of energy systems, builds on implicitly constant relative prices of all non-energy goods and factors. This forbids forcing in KLEM-CHN the above 'price' trajectories straight out of China-MAPLE, because they are inconsistent with the endogenous price system of KLEM-CHN. To address this inconsistency, we develop an original method in three steps. We start by computing proxies of 'bottom-up' energy price trajectories in KLEMCHN (hereafter 'BU KLEM' trajectories) by crossing China-MAPLE-derived trajectories regarding the energy intensity of, and price of energy to, energy supply, with all other elements of the cost structure, taxes and margins applying to each energy consumer price maintained at their base-year values. We compare these trajectories with those inferred from China-MAPLE, and use, at each time step, the closest correspondence across the reconstructed prices to compute what adjustment of KLEM-CHN non-energy costs of energy supply allows bridging the gap between 'BU KLEM' and China-MAPLE variations for that price. Factoring in this non-energy cost adjustment, we finally compute what adjustments of the trade margins on each energy sale allow aligning the other 'BU KLEM' price

\footnotetext{
${ }^{3}$ One simple example to consider is that of the combined constraints of a minimum capacity of renewable power generation and a maximum capacity of coal power generation. As long as the cap on coal capacity is not reached, the marginal cost of electricity is that of coal generation, and depends on whether the existing coal plants are or are not operating at full capacity (additional investment required or not). This marginal cost may be far below the average cost of power supply, which also reflects the specific costs of the renewable quota.
} 
trajectories on their China-MAPLE counterparts. To synthesise, our procedure detects what minimum adjustment of non-energy costs is necessary to bring one of KLEM-CHN energy prices in line with its China-MAPLE counterpart, taking account of both China-MAPLE information on the evolution of average energy costs and its implicit assumption of constant non-energy prices. It then computes what adjustments of the margins on energy sales are necessary to bring the other KLEM-CHN energy prices in line with their own China-MAPLE counterparts taking account of the same set of information and assumptions (see Appendix E).

We repeat this complex procedure and the computation of aggregate energy flows for all time steps and at each iteration of the data import from China-MAPLE into KLEM-CHN. At the end of the convergence process, the cost of energy supply of KLEM-CHN builds on whatever adjustments of nonenergy intensities to energy supply and of agent-specific sales margins are consistent with ChinaMAPLE data, and on endogenous prices.

\section{Scenario exploration}

We now turn to application of the above methodology to the exploration of two scenarios of Chinese energy/economy trajectories up to 2050.

\subsection{Scenario description}

Our Business as usual (BAU) scenario reflects the impact of the 13th Five-Year Plan, covering a wide spectrum of policies at the national and sectoral levels, including energy supply development plans and efficiency standards (see Table F.1 in Appendix F). However, it leaves aside the planned Emission Trading System, whose exact perimeter and provisions regarding the initial distribution of emission rights have not been promulgated yet. Beyond 2020, the BAU scenario assumes general prolongation of the trends inscribed in the $13^{\text {th }}$ Five-Year plan regarding the diffusion rate of efficient technology and renewable options as well as the rate of energy efficiency improvements not embedded in specific 
technology options (e.g. of behavioural nature). Additionally, it assumes gradual structural change of the Chinese economy in the form of a decreasing contribution of industries and an increasing contribution of services to activity, with important bearing on the energy and carbon intensity of growth. The aim of the BAU scenario is to assess current policies and to illustrate their consequences on energy consumptions and $\mathrm{CO}_{2}$ emissions in the long run.

Our deep decarbonisation pathways (DDP) scenario was developed to inform the preparation of China's NDC before the Paris Agreement by illustrating one possible trajectory leading China to a lowcarbon future. This scenario was underpinned by detailed sector-level analysis to explore potential technical solutions for the transition towards deep decarbonisation. Three key pillars of deep decarbonisation were emphasised, which may have a significant impact on the low-carbon transition of China: the improvement of energy efficiency, the replacement of coal and the penetration of electric vehicles in transportation. Exogenous energy efficiency improvements (coupling to KLEM-CHN allows accounting for their costs, see Appendix B and Section 4.3 below) are considered in all end-use sectors (see Table F.1 of Appendix F).

Both our BAU and DDP are therefore scenarios of energy efficiency and technology prescriptions rather than of mitigation objectives. China-MAPLE's optimisation of the Chinese energy system is conditional to such prescriptions. For that reason, the emission reductions of the DDP scenario come at suboptimal costs. Our purpose is indeed the positive description of expected governmental plans rather than the normative description of the optimal pathway to some carbon-control objective. ${ }^{4}$

On the side of economics (in KLEM-CHN), both the BAU and DDP scenarios share a unique set of growth drivers in the form of exogenous trajectories of labour supply and labour productivity gains. The labour

\footnotetext{
${ }^{4}$ Our numerical method would guarantee optimality from the point of view of the minimisation of technical costs only, under constraint of the converged level of economic activity. We would not have any guarantee that the macroeconomic costs of the transition would be minimum.
} 
supply trajectory is that of the International Labour Organisation (ILO, 2014) extrapolated beyond 2020 to reflect projections of the 20 to 69 -year-old Chinese population by the United Nations Population Division (United Nations Development Programme, 2015). The labour productivity trajectory calibrates on this labour supply trajectory and the projection of Chinese GDP by the 2014 New Climate Economy report of the Global Commission on the Economy and Climate (Stern and Calderon, 2014). Both trajectories combine into growth of efficient labour, or potential output growth, of $587 \%$ by 2050 compared to 2010 . The corresponding average annual growth rate is of $4.94 \%$, a marked decline from current trends caused by the decreasing labour supply (Figure 2).

Figure 2 Growth drivers common to the BAU and DDP scenarios

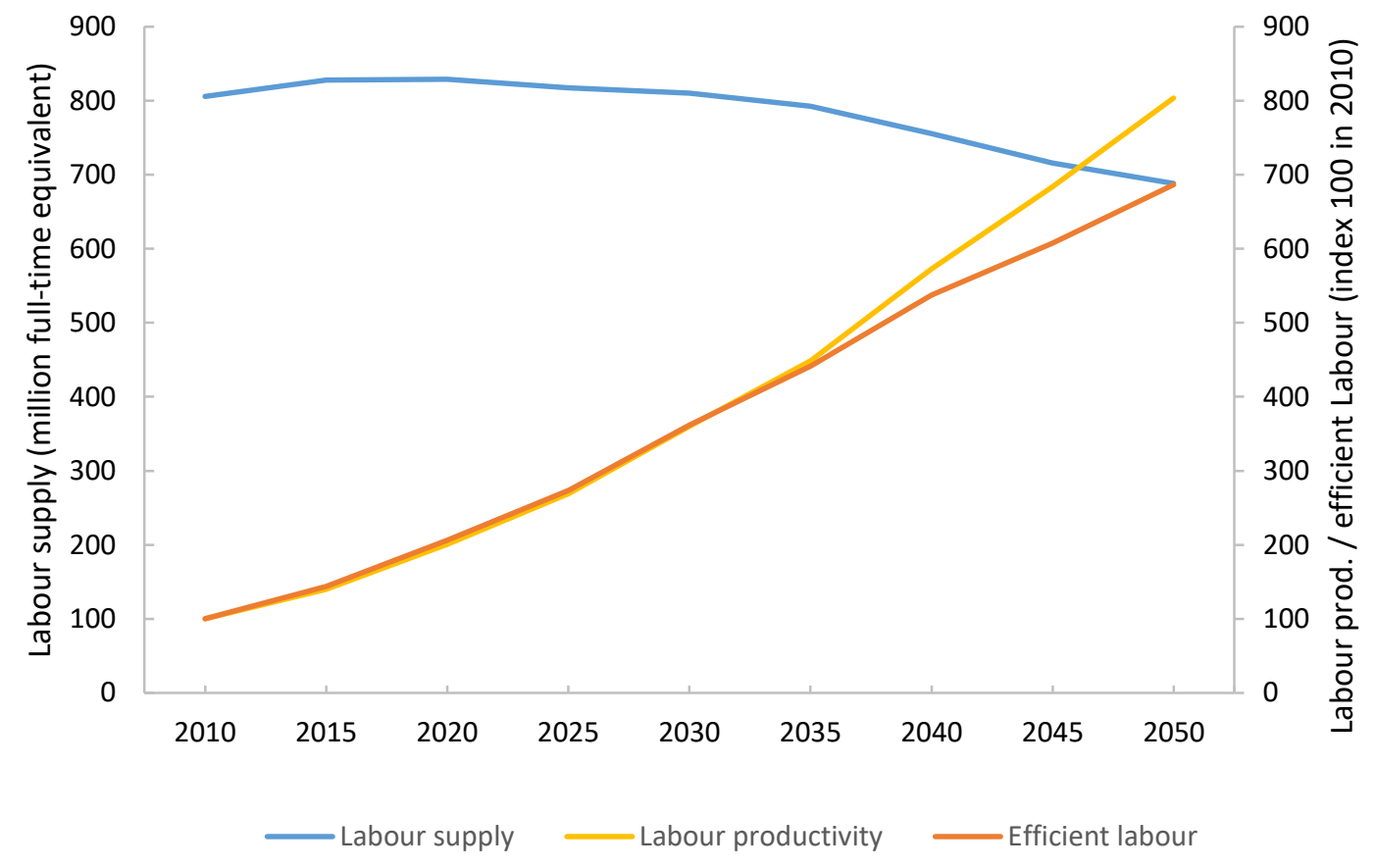

Sources: see text.

Calibration of the investment rate trajectory on the potential growth trajectory (see Appendix B on our choice of a Johansen closure and Appendix D.2 on the calibration) results in investment efforts steadily declining over the projection horizon to reach 28.2\% of GDP in 2050. 


\subsection{Energy systems results}

We start our analysis of energy-systems results by considering energy supply, then moving to energy demand by firms and households, then to energy imports. Under the BAU scenario, primary energy consumption almost doubles between 2010 and 2050, without reaching a peak. The energy mix is still dominated by coal, together with a strong booming of oil consumption in the transportation sector. Energy-related $\mathrm{CO}_{2}$ emissions increase from 8.4 billion tons in 2010 to 13.6 billion tons in 2050 , only plateauing after 2045. With significant mitigation policies in place, under a DDP scenario, carbon emissions peak between 2020 and 2025 at a level above 11.5 billion tons, then reduce to 6.9 billion tons in 2050, a 49.5\% cut from BAU. Primary energy consumption also reaches a maximum of about 5,350 million tons of coal-equivalent (Mtce, in electricity-equivalent terms) in 2030, then slowly reduces to about 4,270 Mtce in 2050. Those trends mark a significant decoupling of carbon emissions from economic growth, leading to $60 \%$ and $84 \%$ reductions of energy intensity per unit of GDP in 2030 and 2050. The energy mix under the DDP scenario expectedly shows a trend towards clean and lowcarbon energies. Electricity becomes a major energy carrier in end-use by a tripling of consumption between 2010 and 2050. The total electricity consumption grows from around 3,000 kWh per person in 2010 to more than $8,700 \mathrm{kWh}$ per person in 2050 . The share of electricity in final energy demand also increases from $18 \%$ in 2010 to $34 \%$ in 2050 . Lastly, the share of non-fossil fuel electricity rises to $72 \%$ in 2050 due to the fast growth of wind and solar, along with the continuous growth of nuclear. 


\section{Figure 3 Primary energy consumptions and $\mathrm{CO}_{2}$ emissions in the $\mathrm{BAU}$ and DDP}

scenarios

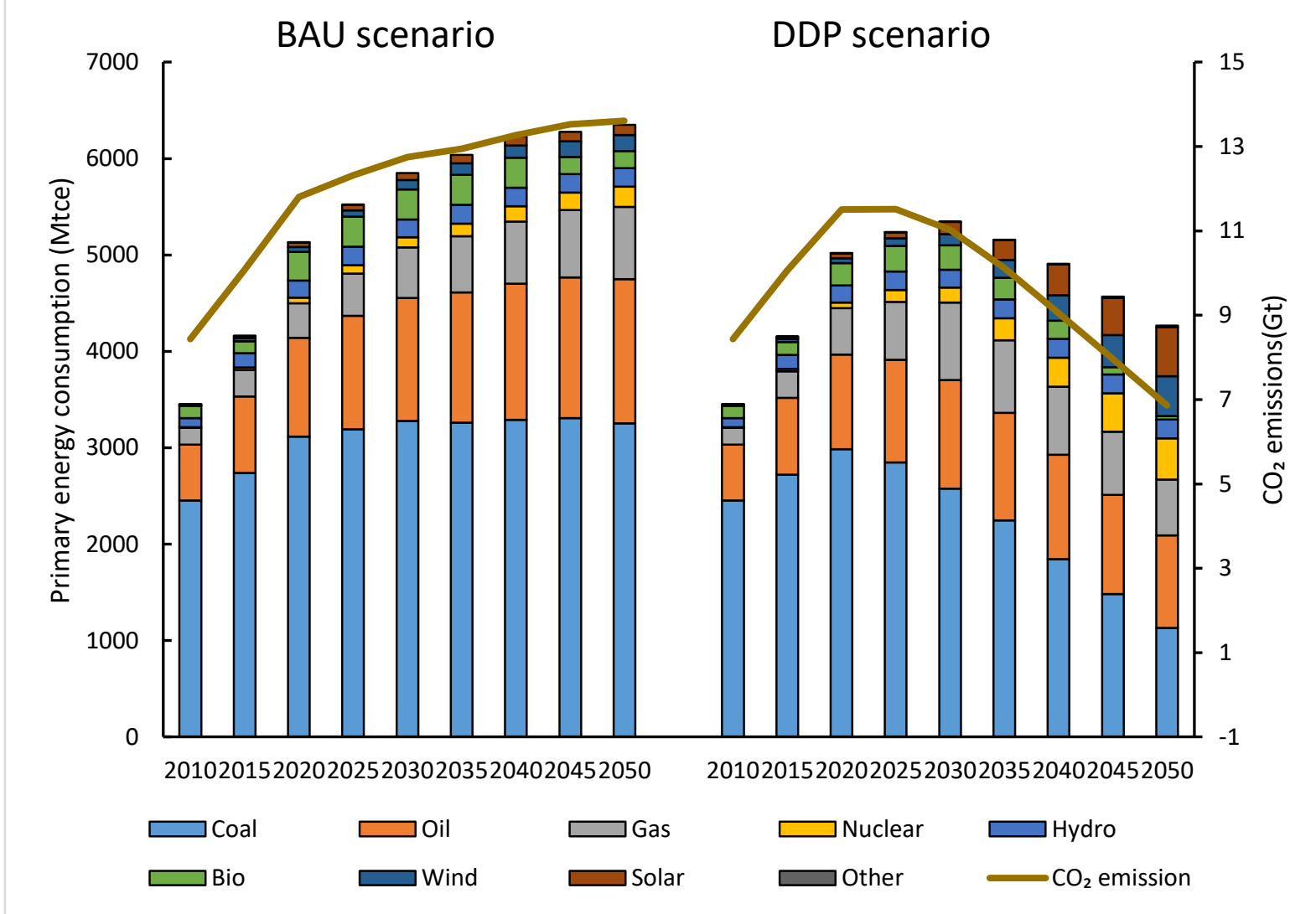

Source: converged China-MAPLE/KLEM-CHN modelling.

Compared with the BAU scenario, the DDP scenario presents significant decarbonisation of the energy supply (see Figure 4 and Figure 5, upper-left panel). Coal is phased out largely due to the fast expansion of renewables together with a steady growth of nuclear. The final energy consumption of firms also presents a similar trend of replacement of both coal and liquid fuels by electricity-mainly through electrification of the vehicle fleet. Notwithstanding, the electricity consumption of firms decreases because of the improvement of energy and resource efficiency. In the household sector, coal is again replaced by electricity, for district heating purposes. The oil consumption of households is also reduced a lot due to the phasing out of internal combustion vehicles and fuel economy improvements. Traditional biomass is also replaced by commercial energy along with the fast urbanization process in China. The consequence of these mix changes is that the DDP scenario significantly reduces energy imports, especially oil imports, leading to an improvement in energy security. The import of gas and 
coal is similar in the BAU and DDP scenarios, reflecting the lower supply cost of imports. Thus, the reduction of coal consumption is achieved through the closure of domestic production capacity rather than a reduction in import.

\section{Figure 4 Structure of energy flow in the BAU and DDP scenarios}

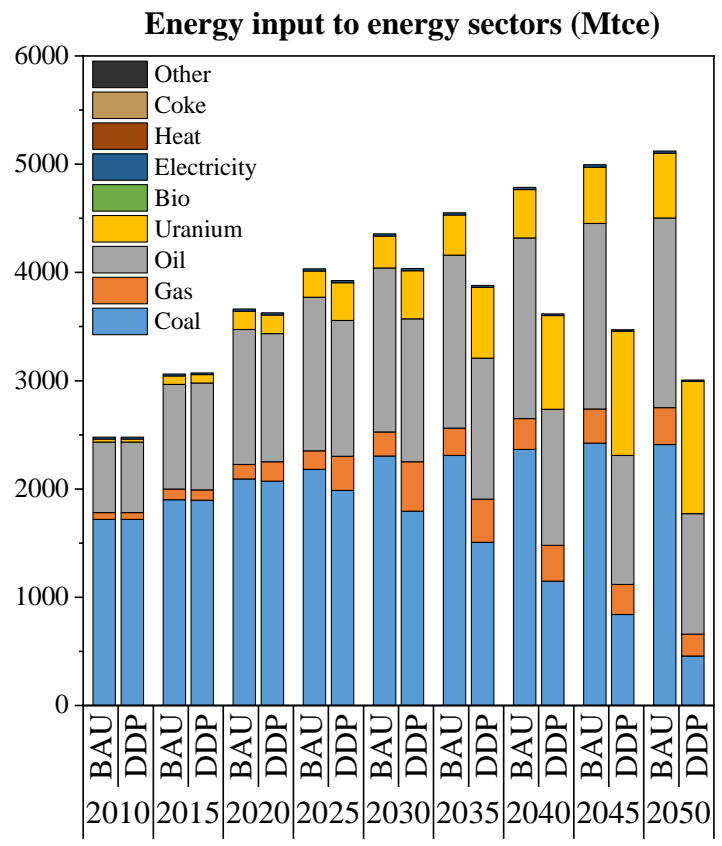

Energy consumption of non-energy sectors (Mtce)
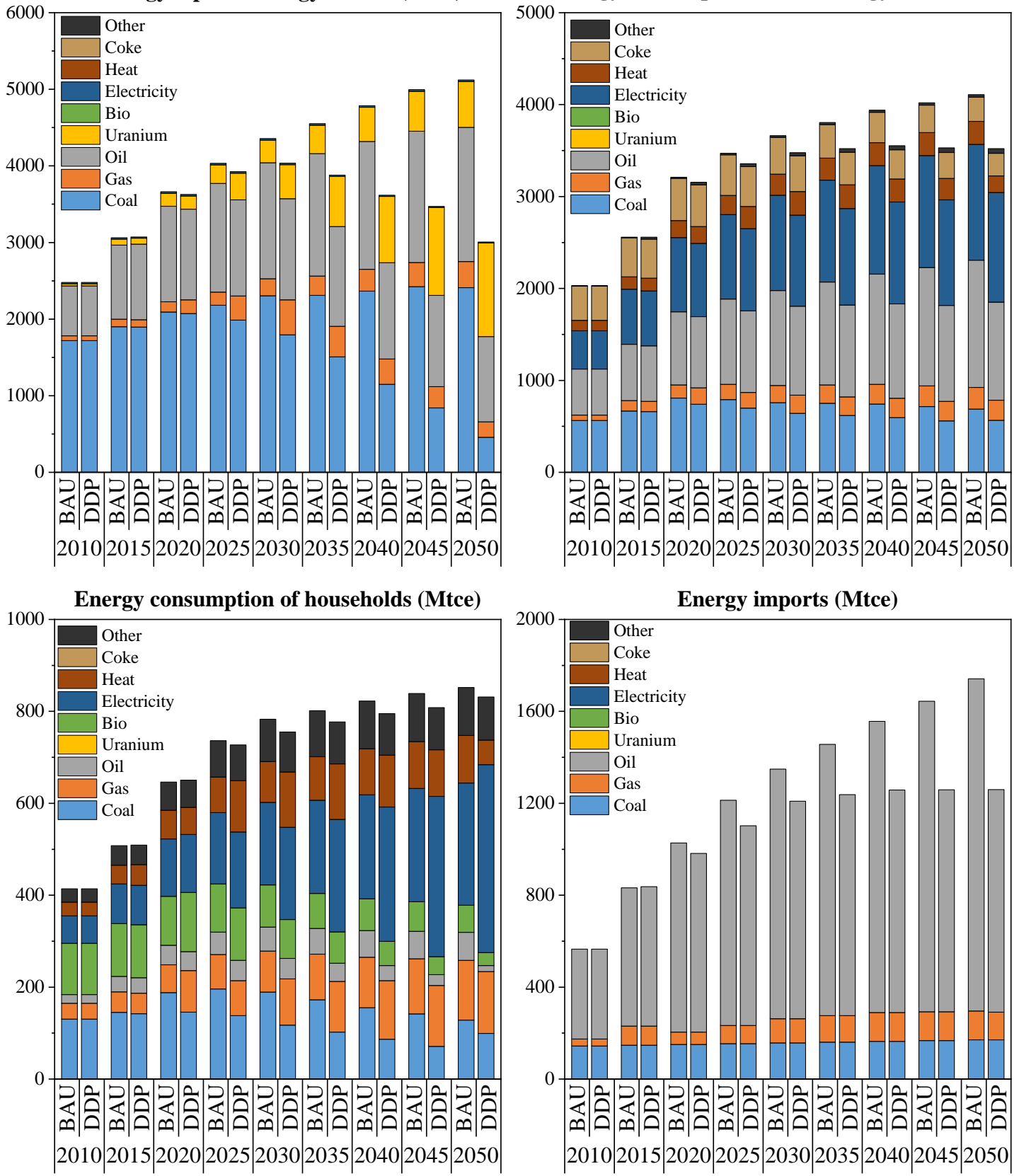

Source: converged China-MAPLE/KLEM-CHN modelling The Energy input to energy sectors aggregates flows for consumption and transformation purposes. 


\subsection{Macroeconomic results}

To ease the interpretation of the macroeconomic trajectories of both scenarios, we start by reporting on the converged values of some of the aggregate energy-system information transferred from ChinaMAPLE to KLEM-CHN.

In BAU, final energy consumptions of firms and households rise sharply up to 2020 then much more moderately to 2050 (Figure 5, upper panels). Comparing the trajectory of firms' consumption to that of potential output (the efficient labour of Figure 2) betrays the large energy efficiency gains of general economic activity in later years projected by China-MAPLE. Total energy expenses of firms and households (Figure 5, lower-right panel), despite rising prices, also progress much less rapidly than potential output. Import volumes (Figure 5, lower-left panel) rise faster than both final consumptions, marking the increasing dependency of Chinese energy supply to foreign sources. Their average price rises slowly in early years, then faster under the influence of increasing prices of all fossil imports. The two trends combine into a convex trajectory of the expenses on energy imports (Figure 5, lower-right panel). However, the sharp slowing down of final demand after 2025 is sufficient to keep the growth of energy import expenses below that of potential output at our end-horizon (compare lower-right panel of Figure 5 to Figure 2). The lower trajectory of households' expenses and the even lower trajectory of firm's expenses, although raw China-MAPLE data do not account for KLEM-CHN feedback loops on prices, point at decreased energy constraints on growth, i.e. at growth that could supersede its potential from efficient labour increases alone. 
Figure 5 Main converged China-MAPLE outputs informing KLEM-CHN in the BAU and DDP scenarios

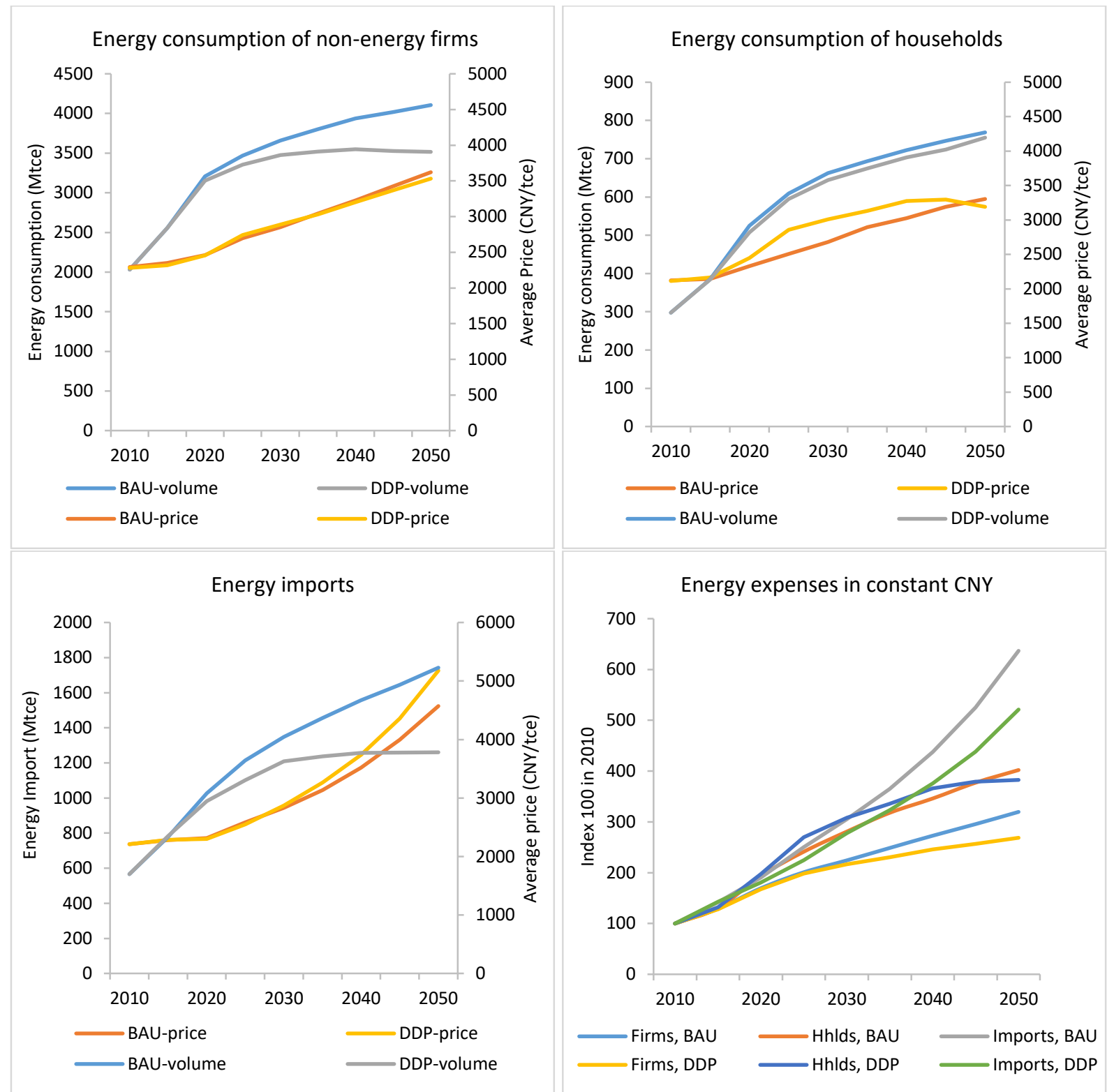

Source: China-MAPLE results. Volume energy consumptions differ from those of Figure 4 because of conceptual differences between energy flow statistics and national accounting (see Appendix C).

Compared to BAU, DDP exhibits consumption volumes of firms growing less rapidly in early years and broadly plateauing after 2030. The consumption volumes of households are also lower, but only marginally so, and the gap to BAU consumptions is even decreasing in later years. Still, the combined energy savings gradually slow down the growth of imported volumes up to an actual plateau from 2040 on. Consequently, the gap with the continually increasing import volumes of BAU rapidly widens. However, because of shifts in the import mix, the average import price is increasingly higher in DDP 
than in BAU. Energy import expenses therefore grow increasingly fast in DDP like they do in BAU, although at slower rates.

Understanding the evolutions of the average prices faced by firms and households requires considering that the 2010 price of one tce of coal is approximately four times below that of one tce of electricity, which is itself approximately two times below that of oil products. The ordering of the three prices remains unchanged through time and across our two scenarios despite the increasing contribution of wind and solar technologies to power supply in DDP. It defines how changes of mix modify average prices.

On the side of firms, DDP prompts substitution of electricity to both coal and oil products from early years on. The savings from substituted oil products consumptions turn out to offset the cost increases from substituted coal consumptions, and the average price barely changes before being processed into KLEM-CHN (see Appendix E). Consequently, firms' expenses grow increasingly slower in DDP than they do in BAU.

On the side of households, electricity similarly substitutes to coal in early years, but to oil products only in later years when electrification of the personal vehicle fleet has had time to develop. The consequence is that the average price of households' energy rises sharply in the short term and remains $8 \%$ to $14 \%$ above BAU values up to 2040 . After 2040 , prices peak then decrease under the combined influence of the quasi phasing-out of oil products consumptions, and cost reductions specific to renewable power supply through 'leaning-by-doing'. Therefore, households' energy expenses under DDP fall below their BAU level in 2050.

More generally, all expense profiles remain below that of potential output (compare the lower-right panel of Figure 5 to Figure 2), which points again at a decreasing energy constraint on growth. However, one important element missing in this analysis of energy prices and flows is the cost of the energy productivity gains in non-energy production-which gains again show in the comparison of the 
trajectories of potential output and firms' energy consumptions. In KLEM-CHN, this cost flows from the assumption of a nested-CES structure to non-energy production (see Appendix B). Energy enters this structure at a point where it trades off with the value-added composite of capital and labour. Consequently, some level of 'autonomous energy efficiency improvement' (AEEI) must be forced to compensate for the decrease of energy intensity described by China-MAPLE (see Equation 4 of Appendix B), lest this decrease would come at a disproportionate value-added cost. We calibrate the trajectory of AEEI as that required to compensate exactly the decrease of energy consumption of the BAU scenario under the condition of potential growth realising. One consequence is that the valueadded intensity of (non-energy) output is going to increase if ever BAU growth supersedes its potential from efficient-labour increases only, as energy-expense trajectories suggest it could. Another consequence is that the sharp decrease of the energy intensity of (non-energy) output from BAU to DDP is going to come at some value-added cost.

Macroeconomic trajectories traced by KLEM-CHN after convergence with the above MAPLE data confirm our intuition that BAU GDP growth could supersede that of efficient labour (compare Figure 2 to Figure 6). The $681 \%$ increase of GDP over 40 years translates in a $5.27 \%$ annual average substantially higher than the $4.94 \%$ average growth of efficient labour supply. As we explained above, this growth in excess to efficient labour growth implies some value-added costs to the MAPLE level of energy consumption by non-energy firms. Detailed KLEM results confirm that the 2050 value-added intensity of non-energy output is $1.5 \%$ higher than it was in 2010 , to allow energy intensity decreasing $72.6 \%$ at that horizon-2.1 points further than the $70.5 \%$ drop inscribed in the AEEl calibrated on potential growth (see above).

Beyond the primary result of GDP growth, the sharp decrease of the investment rate inscribed in the slowing down of efficient labour increases (see Section 4.1 and Appendix D.2) strongly impacts the composition of GDP. With the trade balance and public consumption constant shares of GDP, it is households' consumption that benefits from decreased savings requirements-an expected effect of 
our Johansen closure. Our BAU scenario is thus one of steady activity growth sustained by strong energy efficiency improvements-for a major part but not entirely autonomous ones, with 'soft landing' of the current extremely high investment levels in favour of increased household consumption.

\section{Figure 6 Macroeconomic trajectories of BAU and the difference between BAU and DDP scenarios}

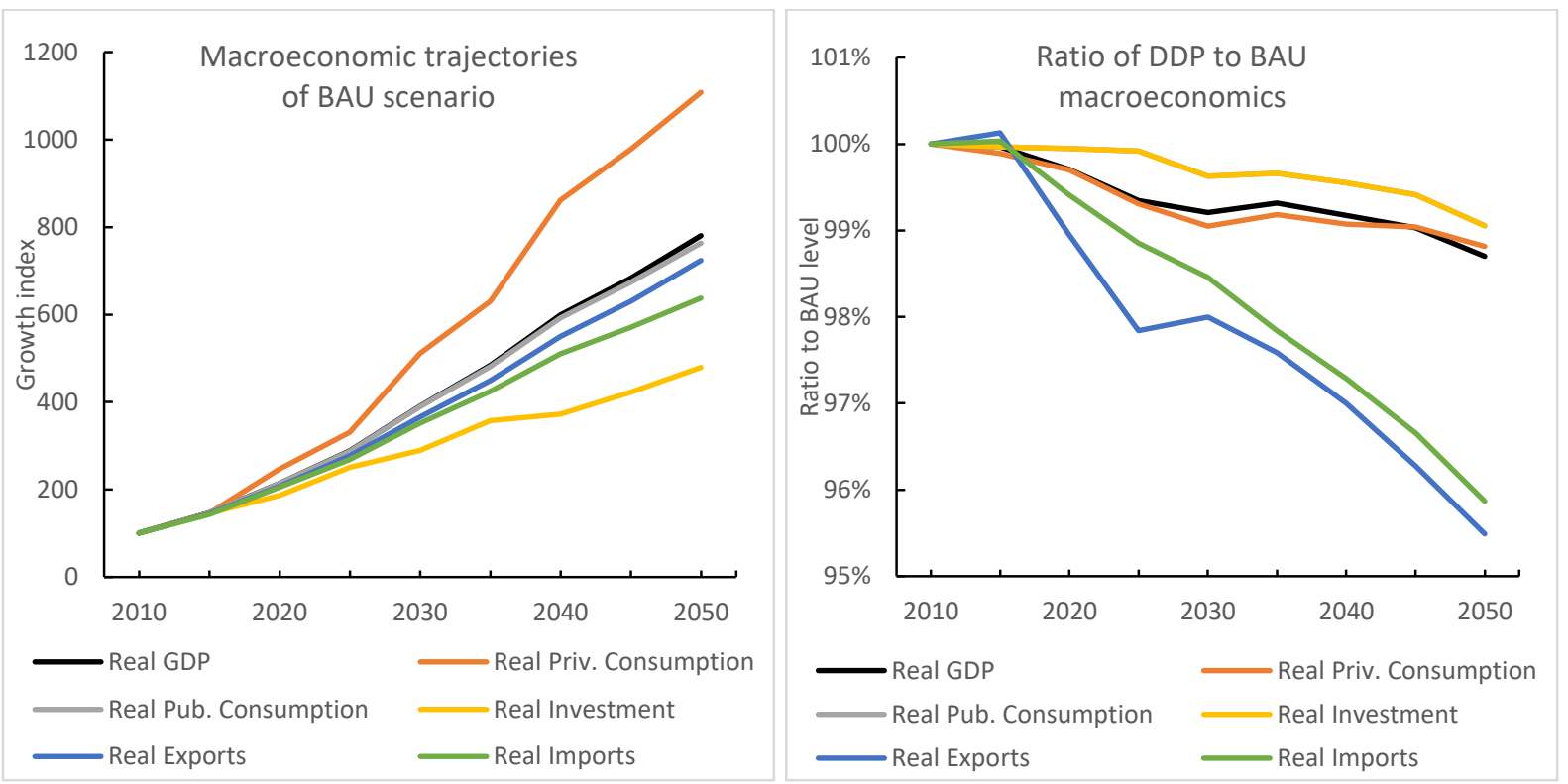

Source: converged KLEM-CHN China-MAPLE modelling. All reported series are deflated from own-price variations using specific chained Fisher indexes. The left-hand graph reports series indexed at 100 in 2010. The right-hand graph reports ratios of DDP series to their BAU equivalents.

KLEM-CHN projects DDP macroeconomics slightly less favourable than those of BAU (Figure 6, right panel). DDP GDP grows $670 \%$ over 40 years to land $1.3 \%$ below its BAU level. Average annual GDP growth recedes to $5.24 \%$. The lag at end horizon is less than one year of growth though, and DDP GDP still performs above exogenous efficient labour gains. The absence of impact of DDP on the average price of energy to non-energy firms (see upper-left panel of Figure 5) partly explains this low activity cost of deep decarbonisation. It allows energy expenses to decrease substantially and compensate partially the higher value-added costs of increased energy efficiency gains. Indeed, detailed results confirm that the value-added intensity of non-energy output at end horizon is significantly higher in DDP than in BAU, at $4.3 \%$ above 2010 level. Importantly, the contained increase and eventual decrease 
of households' energy prices allows households' consumption losses to align on GDP losses, thereby stabilising the structure of GDP expenditures other than investment across both scenarios.

\section{Conclusion}

The macroeconomic cost of climate mitigation is a critical policy question for policymakers and deserves tremendous research efforts. Our study contributes to answer that question by linking a macroeconomic TD model with a detailed BU model and applying the resulting hybrid model to explore energy-economy interactions in China's low-carbon transition. Our methodology benefits from two advantages. Firstly, it rests on an original energy-economy database combining energy and economic flows, thereby maximising the consistency and relevance of our TD and BU model coupling. Secondly, after the iterative exchange to convergence of variables common to the two numerical systems, it offers both a comprehensive, minute description of the Chinese energy system and an aggregate description of Chinese macroeconomics, in full consistency one with the other.

Although most studies based on CGE models project high economic costs from deep decarbonisation of the energy system, our results suggest that those costs may be overestimated. The higher costs of CGE-based studies may be partly due to the biased policy consideration focusing on carbon pricing policies and giving much less attention to efficiency measures and technology prescriptions in energy supply and end-use sectors. If the substitution between energy and other factors is not responding, the introduction of high energy or carbon prices may induce high costs to the economy. Our results highlight the importance of energy efficiency measures in industry sectors, not only as mitigation policies but also as hedging strategies against the macroeconomic impacts of low-carbon transition, particularly their costs in terms of increased value-added intensity of production. They also demonstrate how the electrification of personal mobility allows cutting down the costs of decarbonisation to households in the longer term by gradually phasing-out costly (imported) oil products consumptions. 
Additionally, improvements of energy efficiency will lead to the reduction of fossil-fuel demand and hence to a lower price for fossil fuels, especially coal. The combination of those two effects leads to barely changed average energy prices for firms, which mitigates the investment costs of the lowcarbon transition.

Compared with BAU, our DDP scenario consequently shows a small macroeconomic cost, equal to a lag of less than one year of growth in 2050. Taking into account the large expected health benefits from reduced air pollution could therefore turn the scenario comparison in favour of the DDP. Our results also show that the Chinese household sector needs careful scrutiny in a DDP scenario due to its growing energy expense in the near term, when relatively costly renewable electricity replaces both direct coal consumptions and consumption of coal-fired electricity. These increased energy expenses raise the concern of both appropriate policy design to alleviate their burden, and distributional effect among different income groups. However, the concern appears to be only transitory. Households' energy expenses in a DDP scenario pass below those under BAU after 2040, thanks to the phasing-out of costly (imported) oil products consumptions via electrification of personal vehicles, and to efficiency gains in renewable electricity.

A natural prolongation of our research is the mobilisation of the IMACLIM model as a multisector generalisation of KLEM (see footnote 2), which will increase the connection points between our macroeconomic and bottom-up modelling, as well as allow refining our representation of the crowding-out of productive capital by addressing structural change issues. Additionally, an in-depth study on the electricity sector would provide further policy insights considering the importance of electrification processes on the evolution of both firms' and households' average energy prices. Yet another potential implementation of our modelling framework regards the exploration of 'LED' (low energy demand) scenarios, which have been highlighted as an alternative to significant negative emission technologies (Grubler et al., 2018). 


\section{Appendix A. The bottom-up model China-MAPLE}

The China-Multi-pollutant Abatement Planning and Long-Term Benefit Evaluation Model, ChinaMAPLE, is an energy-system optimization model based on The Integrated MARKAL-EFOM System (TIMES) model generator (Loulou et al., 2016). TIMES has been developed and is maintained under the International Energy Agency's Energy Technology Systems Analysis Programme (IEA-ETSAP). In ChinaMAPLE, the model generator translates the customized energy system into a linear optimization problem to minimize the overall system cost within a set of technical and economic constraints. The objective of the model is to identify the least-cost way to meet energy-service demands through minimisation of the total discounted system cost over the entire modelling time horizon. The system cost consists of investment, operation and maintenance, and energy input costs of all the technologies invested in and operated up to the end horizon. Therefore, the model assumes perfect foresight and perfect competition.

China-MAPLE portrays the entire energy system of China with a detailed description of thousands of technologies in energy supply, process, conversion and end-use sectors (Figure A.1). 


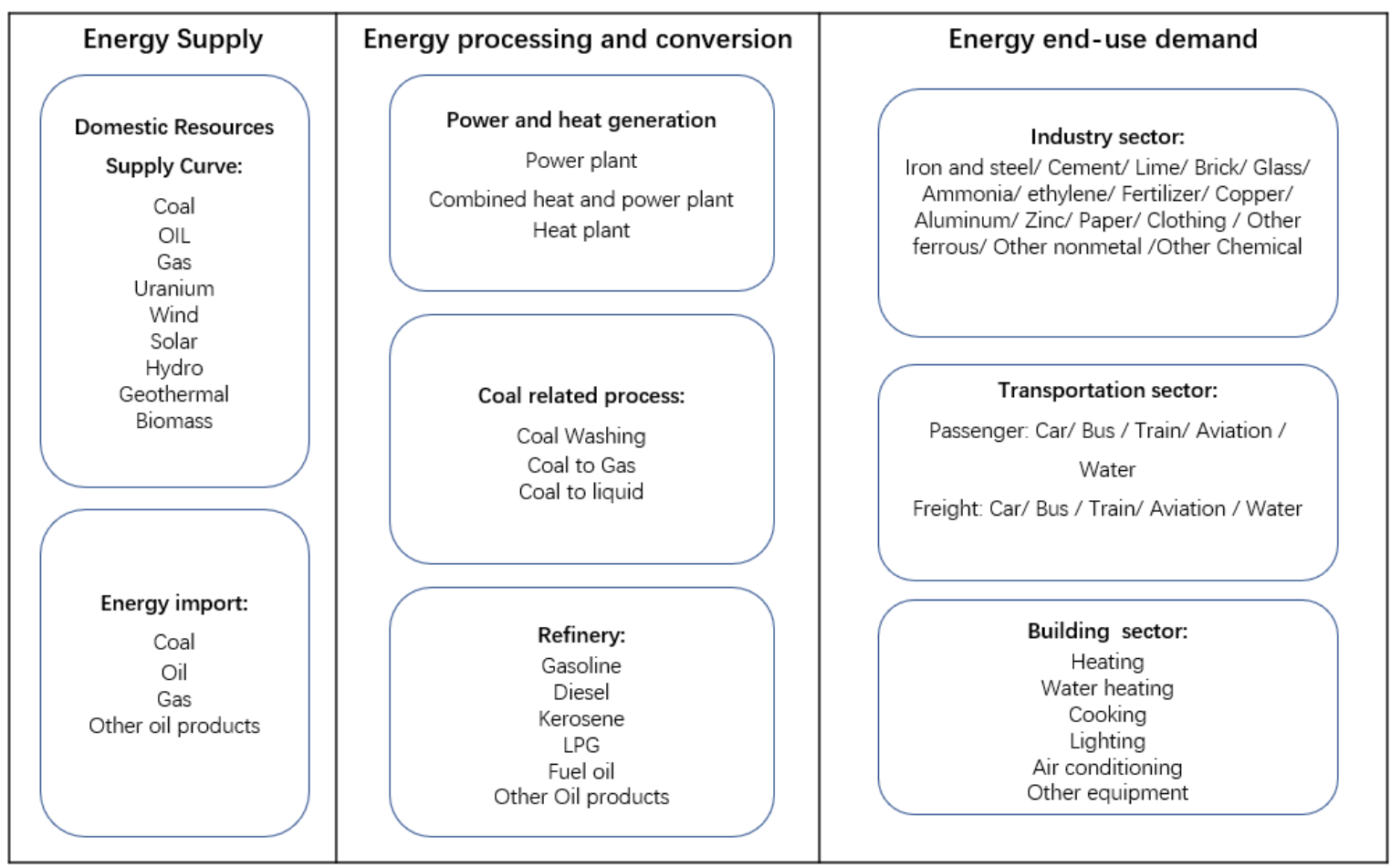

Energy supply describes resource exploration and extraction in different regions of China through supply curves for primary energy, including coal, oil, gas, and nuclear, as well as renewables. Imported energy is also modelled through different supply curves to represent cost variants among different producing countries. The energy process and conversion module covers activities in coal washing, coking, oil refining, and electricity and heat generation. These technologies are represented in ChinaMAPLE by the parameters of resource endowment, efficiency, investment cost, fixed and variable operation costs. The energy end-use module captures the activities of end-use sectors, such as industry, transportation and the building sector (i.e., the physical output of industrial products, the passengerkilometres travelled and ton freight- kilometres transported, the lighting, cooking, heating, water heating, air-conditioning, and use of electrical equipment by households). Those activities are projected according to socio-economic assumptions and the plans of the government. When the model is used alone, the socio-economic assumptions are exogenous; when coupled to KLEM-CHN, they are obtained from KLEM-CHN. Carbon dioxide emissions and important air-pollutant emissions 
associated with fossil-fuel consumption are also modelled. For more information about China-MAPLE, please refer to (Yang and Teng, 2017; Yang and Teng, 2018; Yang et al., 2017; Yang et al., 2018).

\section{Appendix B. Top-Down model KLEM-CHN}

The macroeconomic core of KLEM is a dynamic, recursive model deriving from a Solow-Swan growth model. KLEM-CHN pictures economic growth in 5-year time steps as driven by exogenous assumptions on the supply and productivity of labour. The vector of domestic energy and non-energy outputs at year $t$, is a function of the stock of capital, labour force and intermediate consumption of energy and non-energy goods. The function varies with year $t$ via exogenous labour productivity gains (the Harrodneutral assumption on technical progress). Capital stock dynamics follow the standard accumulation rule at a constant depreciation rate with explicit accounting of year-to-year variations between 5-year time steps (see Appendix D.3). Considering the 5-year interval and 2050 horizon of KLEM-CHN, both its labour and capital markets clear by adjustments of the wage $w$ and the rental price of capital $p_{K}$. Its trade balance is exogenous (Equation 13 of Appendix B) following neoclassical practice but its macroeconomic closure is on domestic savings rather than on investment, following Johansen (1960), to reflect the degree of governmental control on the Chinese economy. This implies a growth trajectory more robust to scenario variants at the cost of final consumption variations-which we will duly report when analysing scenarios. The investment effort is set as a share of GDP (Equation 9 of Appendix B) that evolves to warrant that the capital stock grows apace with efficient labour when potential growth, defined by efficient labour increases, concretises (see Appendix D.2).

KLEM models non-energy production as a nested structure of Constant Elasticity of Substitution (CES) trade-offs between inputs (Equations 2 to 6 of Appendix B), and non-energy trade as elastic to prices (Equations 10 and 11 of Appendix B). However, linkage to China-MAPLE translates into full exogeneity of the energy system. The growth trajectories traced by KLEM-CHN thus build around exogenous energy consumptions and trade as well as around exogenous assumptions on the cost structure of 
energy supply beyond its own energy intensity and on the specific margins (differences of consumer prices to average supply costs) on each energy sale. For lack of easily exploitable information in ChinaMAPLE, the costs of potential energy savings in the non-energy sector proceed from the nested CES specification as incremental value-added costs, under the assumption that 'business-as-usual' ChinaMAPLE energy consumptions and non-energy output increasing at the pace of efficient labour supply define cost-free energy-productivity gains ('autonomous energy efficiency improvements', AEEI) ${ }^{5}$.

These constraints on energy volumes, costs and prices weigh on economic growth and non-energy consumption by reserving part of value-added to exogenous energy expenses and endogenous, attached energy-efficiency costs and part of primary factor endowments to the supply of some exogenous volume of energy.

For reference purposes, we list all variables and parameters below (Table B.1), with the exception of a series of constant parameters calibrated on 2010 values, which we introduce with equations when necessary. The model counts 43 variables and 43 equations: equations 1, 14, 15, 20, 27, 29 and 32 cover both sectors and thus count twice; equation 28 defines the prices of the 10 matrix and thus counts 4 times. All equations prevail at each time period of the model, from 2010 (calibration year) to 2050 in 5-year steps. However, we drop time index $t$ except when necessary. We index good-specific notations with subscript $E$ for the aggregate energy good and subscript $Q$ for the aggregate nonenergy good.

\section{Table B.1 KLEM-CHN notations}

\begin{tabular}{lll}
\hline Notation & Description & Status \\
\hline$L$ & Labour endowment & 1 parameter from ILO and UNPD (see Section 3.1) \\
$K$ & Capital endowment & 1 parameter calibrated in 2010 then from perpetual \\
& & inventory (see Appendix D).
\end{tabular}

\footnotetext{
${ }^{5}$ For a recent survey on AEEI see Bataille and Melton (2017). KLEM-CHN's trade-off between aggregate value-added and energy and its specification of AEEl are similar to those of Bataille and Melton's CGE model.
} 


\begin{tabular}{|c|c|c|}
\hline$L_{i}$ & Volume of labour in good $i$ production & 2 variables \\
\hline$K_{i}$ & Capital stock in good $i$ production & 2 variables \\
\hline$K L$ & $\begin{array}{l}\text { Value-added aggregate of } K_{Q} \text { and } L_{Q} \text { in the } \\
\text { production of } \operatorname{good} Q\end{array}$ & 1 variable set at 1500 in 2010 without loss of generality. \\
\hline$K L E$ & $\begin{array}{l}\text { Aggregate of value-added } K L \text { and energy } E \text { in } \\
\text { the production of good } Q\end{array}$ & 1 variable set at 1500 in 2010 without loss of generality. \\
\hline$E_{i}$ & $\begin{array}{l}\text { Consumption of energy in the production of } \\
\text { good } i\end{array}$ & 2 parameters from China-MAPLE (see Appendix E) \\
\hline$C_{i}$ & Consumption of good $i$ by households & $\begin{array}{l}1 \text { variable } C_{Q}, \\
1 \text { parameter } C_{E} \text { from China-MAPLE (see Appendix E) }\end{array}$ \\
\hline$\phi_{E}$ & $\begin{array}{l}\text { Energy productivity in the production of KLE } \\
\text { aggregate (index } 1 \text { in 2010) }\end{array}$ & $\begin{array}{l}1 \text { parameter calibrated on natural growth and } E_{Q} \text { of the } \\
\text { BAU scenario (see Equation 4) }\end{array}$ \\
\hline$G_{Q}$ & $\begin{array}{l}\text { Consumption of good } Q \text { by public } \\
\text { administrations }\end{array}$ & 1 variable \\
\hline$I_{Q}$ & Immobilisation of good $Q$ through investment & 1 variable \\
\hline$X_{i}$ & Export of good $i$ & $\begin{array}{l}1 \text { variable } X_{Q} \text {, } \\
1 \text { parameter } X_{E} \text { from China-MAPLE (see Appendix E) }\end{array}$ \\
\hline$M_{i}$ & Import of good $i$ & $\begin{array}{l}1 \text { variable } M_{Q} \\
1 \text { parameter } M_{E} \text { from China-MAPLE (see Appendix E ) }\end{array}$ \\
\hline$Y_{i}$ & Output of good $i$ & 2 variables \\
\hline$S_{i}$ & Total (domestic and foreign) supply of good $i$ & 2 variables \\
\hline$\alpha_{i j}$ & Intensity of good $j$ in good $i$ & $\begin{array}{l}3 \text { variables } \alpha_{Q Q}, \alpha_{E Q}, \alpha_{E E}, \\
1 \text { parameter } \alpha_{Q E} \text { from China-MAPLE (see Appendix E) }\end{array}$ \\
\hline$\lambda_{i}$ & Labour intensity of good $i$ & $\begin{array}{l}1 \text { variable } \lambda_{Q}, \\
1 \text { parameter } \lambda_{E} \text { from China-MAPLE (see Appendix E) }\end{array}$ \\
\hline$\kappa_{i}$ & Capital intensity of good $i$ & $\begin{array}{l}1 \text { variable } \kappa_{Q} \\
1 \text { parameter } \kappa_{E} \text { from China-MAPLE (see Appendix E) }\end{array}$ \\
\hline$w$ & Wage & 1 variable set at 100 in 2010 without loss of generality. \\
\hline$p_{K}$ & Rental price of capital & 1 variable \\
\hline$p_{K L}$ & Price of value-added $K L$ in good $Q$ production & 1 variable \\
\hline$p_{K L E}$ & Price of aggregate $K L E$ in good $Q$ production & 1 variable \\
\hline$p_{Y_{i}}$ & Output price of good $i$ & $\begin{array}{l}2 \text { variables, } p_{Y Q} \text { set at } 1000 \text { in } 2010 \text { without loss of } \\
\text { generality. }\end{array}$ \\
\hline$p_{S_{i}}$ & Average price of good $i$ supply & 2 variables \\
\hline$p_{i j}$ & Price of good $i$ used in the production of good $j$ & 4 variables \\
\hline$p_{C_{i}}$ & Price of good $i$ for households & 2 variables \\
\hline$p_{G_{Q}}$ & Price of good $Q$ for public administrations & 1 variable \\
\hline$p_{I_{Q}}$ & Price of good $Q$ for investment & 1 variable \\
\hline$p_{X_{i}}$ & Export price of good $i$ & $\begin{array}{l}1 \text { variable } p_{X_{Q^{\prime}}} \\
1 \text { parameter } p_{X_{E}} \text { from China-MAPLE (see Appendix E) }\end{array}$ \\
\hline$p_{M_{i}}$ & Import price of good $i$ & $\begin{array}{l}1 \text { parameter } p_{M_{Q}} \text { price of the numéraire } M_{Q} \text {, set at } 1000 \\
\text { in } 2010 \text { without loss of generality } \\
1 \text { parameter } p_{M_{E}} \text { from China-MAPLE (see Appendix E) }\end{array}$ \\
\hline$C P I$ & Consumer Price Index (chained Fisher index) & 1 variable \\
\hline MPI & Import Price Index (chained Fisher index) & 1 variable \\
\hline
\end{tabular}




\begin{tabular}{|c|c|c|}
\hline$u$ & Unemployment rate & 1 variable (constant per Equation 19) \\
\hline$G D P$ & Gross Domestic Product & 1 variable \\
\hline$B$ & Trade balance value & 1 variable \\
\hline$\alpha_{K L}$ & Coefficient of $K_{Q}$ in the $K L$ CES function & 1 parameter (472.5) calibrated in 2010 \\
\hline$\beta_{K L}$ & Coefficient of $L_{Q}$ in the $K L$ CES function & 1 parameter (758.3) calibrated in 2010 \\
\hline$\sigma_{K L}$ & $\begin{array}{l}\text { Elasticity of substitution between } K_{Q} \text { and } L_{Q} \text { in } \\
K L\end{array}$ & 1 parameter (0.4) from Okagawa and Ban (2008) \\
\hline$\alpha_{K L E}$ & Coefficient of $K L$ in the $K L E$ CES function & 1 parameter (0.8399) calibrated in 2010 \\
\hline$\beta_{K L E}$ & Coefficient of $\alpha_{E Q} Y_{Q}$ in the $K L E$ CES function & 1 parameter (0.1957) calibrated in 2010 \\
\hline$\sigma_{K L E}$ & Elasticity of substitution between $K L$ and $\alpha_{E Q} Y_{Q}$ & 1 parameter (0.6) from Okagawa and Ban (2008) \\
\hline$\alpha_{Y}$ & Coefficient of $K L E$ in the $Y_{Q}$ CES function & 1 parameter $\left(5.01310^{-4}\right)$ calibrated in 2010 \\
\hline$\beta_{Y}$ & Coefficient of $\alpha_{Q Q} Y_{Q}$ in the $Y_{Q}$ CES function & 1 parameter (0.3289) calibrated in 2010 \\
\hline$\sigma_{Y}$ & $\begin{array}{l}\text { Elasticity of substitution between } K L E \text { and } \\
\alpha_{Q Q} Y_{Q} \text { in } Y_{Q}\end{array}$ & 1 parameter (0.4) from Okagawa and Ban (2008) \\
\hline$\sigma_{w u}$ & Elasticity of real wage to the unemployment rate & 1 parameter (-0.1) from Blanchflower and Oswald (2005) \\
\hline$\sigma_{M p}$ & $\begin{array}{l}\text { Elasticity to relative prices of the share of } \\
\text { imports in total non-energy supply }\end{array}$ & $\begin{array}{l}1 \text { parameter (0.92) from Aziz and Li (2008) (see Equation } \\
\text { 10) }\end{array}$ \\
\hline$\sigma_{X p}$ & $\begin{array}{l}\text { Elasticity to relative prices of the non-energy } \\
\text { export trend }\end{array}$ & $\begin{array}{l}1 \text { parameter (1.55) from Aziz and Li (2008) (see Equation } \\
\text { 11) }\end{array}$ \\
\hline$\delta$ & Depreciation rate of the capital stock & 1 parameter (0.096) from Zhang et al. (2004). \\
\hline$s_{G}$ & Ratio of public expenditure to GDP & 1 parameter $(0.1277)$ calibrated in 2010 \\
\hline$s_{I}$ & Ratio of investment to GDP & $\begin{array}{l}1 \text { parameter calibrated on the potential growth and } \\
\text { depreciation rates assumptions (see Appendix D.2) }\end{array}$ \\
\hline$\tau_{S T_{i}}$ & Sales tax on good $i$ sales & 2 parameters $\left(3.33310^{-2}, 3.33310^{-2}\right)$ calibrated in 2010 \\
\hline$\tau_{Y i}$ & Output tax on good $i$ production & 2 parameters $\left(3.33310^{-2}, 3.33310^{-2}\right)$ calibrated in 2010 \\
\hline$\tau_{M S_{i j}}$ & $\begin{array}{l}\text { Specific margin on good } i \text { sales to good } j \\
\text { production }\end{array}$ & $\begin{array}{l}2 \text { parameters } \tau_{M S_{Q i}} \text { calibrated in } 2010 \text { (nil), } \\
2 \text { parameters } \tau_{M S_{E i}} \text { from China-MAPLE (see Appendix E) }\end{array}$ \\
\hline$\tau_{M S C_{i}}$ & Specific margin on good $i$ sales to households & $\begin{array}{l}1 \text { parameter } \tau_{M S C_{Q}} \text { calibrated in } 2010 \text { (nil), } \\
1 \text { parameter } \tau_{M S C_{E}} \text { from China-MAPLE (see Appendix E) }\end{array}$ \\
\hline$\tau_{M S X_{i}}$ & Specific margin on good $i$ exports & $\begin{array}{l}1 \text { parameter } \tau_{M S X_{Q}} \text { calibrated in } 2010 \text { (nil) } \\
1 \text { variable } \tau_{M S X_{E}}\end{array}$ \\
\hline
\end{tabular}

\section{B.1 Production}

Trade-offs in the production of the energy good are exogenous assumptions flowing from the ChinaMAPLE model (see Appendix E). The only required equation is the breakdown of primary energy inputs into energy transformation - the equation holds for the non-energy sector too:

$$
E_{i}=\alpha_{E i} Y_{i}
$$




\section{Figure B.1 Production structure of the non-energy good}



At the foot of the tree, capital and labour trade off with a constant $\sigma_{K L}$ elasticity of substitution to form a $K L$ aggregate. The mobilized quantity of labour $L_{Q}$ is augmented by a productivity factor $\phi$ : $K L=\left(\alpha_{K L} K_{Q}^{\rho_{K L}}+\beta_{K L}\left(\phi L_{Q}\right)^{\rho_{K L}}\right)^{\frac{1}{\rho_{K L}}}$, with here and elsewhere, for convenience, $\rho_{i}=\frac{\sigma_{i}-1}{\sigma_{i}}$. Facing prices $p_{K}$ and $p_{L}$, cost minimization induces

$$
\begin{gathered}
L_{Q}=\frac{1}{\phi}\left(\frac{\phi \beta_{K L}}{p_{L}}\right)^{\sigma_{K L}}\left(\alpha_{K L}^{\sigma_{K L}} p_{K}^{1-\sigma_{K L}}+\beta_{K L}^{\sigma_{K L}}\left(\frac{p_{L}}{\phi}\right)^{1-\sigma_{K L}}\right)^{-\frac{1}{\rho_{K L}}} K L \\
K_{Q}=\left(\frac{\alpha_{K L}}{p_{K}}\right)^{\sigma_{K L}}\left(\alpha_{K L}^{\sigma_{K L}} p_{K}{ }^{1-\sigma_{K L}}+\beta_{K L}^{\sigma_{K L}}\left(\frac{p_{L}}{\phi}\right)^{1-\sigma_{K L}}\right)^{-\frac{1}{\rho_{K L}}} K L
\end{gathered}
$$

\footnotetext{
${ }^{6}$ Our choice of 'KL-E' rather than 'KE-L' nesting reflects the recommendation of van der Werf (2008) and the most common practice for both China and other country models. Feng and Zhang (2018) advocate 'KE-L' nesting in the case of China only because they assess several estimations collectively, whereas their best estimation of 'KL-E' nesting performs slightly better than their best estimation of ' $\mathrm{KE}-\mathrm{L}$ ' nesting.
} 
Higher up the tree, aggregate factor $K L$ (value-added) and energy $E_{Q}$ again trade off with a constant $\sigma_{K L E}$ elasticity of substitution to form a $K L E$ aggregate. However, $E_{Q}$ is forced following China-MAPLE results (see Section 3.3 and Appendix E) at levels much lower than potential growth (the growth of efficient labour $\phi L$ ), even in business-as-usual scenarios. Accommodating such intensity drops under standard values of $\sigma_{K L E}$ would result in implausible increases of the required $K L$ intensity. To redress this bias, we introduce autonomous efficiency gains to $E_{Q}$ (i.e., autonomous energy efficiency improvements AEEI) in the form of productivity gains $\phi_{E}$. The corresponding $K L E=\left(\alpha_{K L E} K L^{\rho_{K L E}}+\right.$ $\left.\beta_{K L E}\left(\phi_{E} E_{Q}\right)^{\rho_{K L E}}\right)^{\frac{1}{\rho_{K L E}}}$ yields:

$$
K L=\left(\frac{K L E \rho_{K L E}}{\alpha_{\mathrm{KLE}}}-\frac{\beta_{\mathrm{KLE}}}{\alpha_{\mathrm{KLE}}}\left(\phi_{E} E_{Q}\right)^{\rho_{K L E}}\right)^{\frac{1}{\rho_{K L E}}}
$$

We calibrate $\phi_{E}$ in such a way that $\phi_{E} E_{Q}$ ('efficient $E_{Q}$ ' or the actual energy service rendered by $E_{Q}$ ) grows apace with natural growth in business-as-usual (BAU) conditions, i.e. we make the assumption that the energy efficiency gains of the non-energy sector in BAU conditions do not require increased value-added expenses. This will define the value-added costs of the increased energy-consumption cuts of any scenario more ambitious than BAU.

On the tier immediately above, the $K L E$ aggregate and non-energy input $\alpha_{Q Q} Y_{Q}$ trade off with a constant $\sigma_{Y}$ elasticity of substitution to form domestic output $Y_{Q}$. Facing prices $p_{K L E}$ and $p_{Q Q}$, cost minimization induces

$$
\begin{gathered}
K L E=\left(\frac{\alpha_{\mathrm{Y}}}{p_{K L E}}\right)^{\sigma_{\mathrm{Y}}}\left(\alpha_{\mathrm{Y}}^{\sigma_{\mathrm{Y}}} p_{K L E}^{1-\sigma_{\mathrm{Y}}}+\beta_{\mathrm{Y}}^{\sigma_{\mathrm{Y}}} p_{Q Q}^{1-\sigma_{\mathrm{Y}}}\right)^{-\frac{1}{\rho_{\mathrm{Y}}}} Y_{Q} \\
\alpha_{Q Q} Y_{Q}=\left(\frac{\beta_{\mathrm{Y}}}{p_{Q Q}}\right)^{\sigma_{\mathrm{Y}}}\left(\alpha_{\mathrm{Y}}^{\sigma_{\mathrm{Y}}} p_{K L E}^{1-\sigma_{\mathrm{Y}}}+\beta_{\mathrm{Y}}^{\sigma_{\mathrm{Y}}} p_{Q Q}^{1-\sigma_{\mathrm{Y}}}\right)^{-\frac{1}{\rho_{\mathrm{Y}}}} Y_{Q}
\end{gathered}
$$




\section{B.2 Final consumption and investment}

Household consumption of energy $C_{E}$ is exogenous (see Appendix E) while household consumption of the non-energy good $C_{Q}$ adjusts to close the model considering the domestic savings demand resulting from the investment and trade balance assumptions ('Johansen' closure, see above).

Public spending $p_{G_{Q}} G_{Q}$ is a constant share $s_{G}$ of GDP (public spending in energy goods is zero by national accounting convention):

$$
p_{G_{Q}} G_{Q}=s_{G} G D P
$$

with $G D P$ defined on the expenditure side as

$$
G D P=\sum_{i=E, Q} p_{C_{i}} C_{i}+p_{G_{Q}} G_{Q}+p_{I_{Q}} I_{Q}+\sum_{i=E, Q} p_{X_{i}} X_{i}-\sum_{i=E, Q} p_{M_{i}} M_{i}
$$

Investment expenses $p_{I_{Q}} I_{Q}$ are an exogenous ratio $s_{I}$ of GDP (investment in energy goods is nil):

$$
p_{I_{Q}} I_{Q}=s_{I} G D P
$$

See Appendix D.2 for the calibration of the investment path.

\section{B.3 International trade}

Energy imports and exports $M_{E}$ and $X_{E}$ are exogenous, dictated by China-MAPLE results. For the nonenergy good, the share of imports $M_{Q}$ in total supply $S_{Q}$ has a $\sigma_{M p}$ elasticity to terms-of-trade:

$$
\frac{M_{Q}}{s_{Q}}=A_{M}\left(\frac{p_{Y_{Q}}}{p_{M_{Q}}}\right)^{\sigma_{M_{p}}}
$$

with $A_{M}$ one constant calibrated on 2010 data. Similarly, the exported share of total supply follows:

$$
\frac{X_{Q}}{s_{Q}}=A_{X}\left(\frac{p_{X_{Q}}}{p_{M_{Q}}}\right)^{\sigma_{X_{p}}} .
$$

with $A_{X}$ one constant calibrated on 2010 data. (Aziz and Li, 2008)The trade balance $B$ is: 


$$
B=\sum_{i=E, Q} p_{X_{i}} X_{i}-p_{M_{i}} M_{i}
$$

It is exogenous in the sense that its share to GDP maintains at a constant $A_{B}$ ratio (calibrated on 2010 data) via endogenous adjustments of the real effective exchange rate (the ratio of the CPI to the foreign price index, which is not computed):

$$
\frac{B}{G D P}=A_{B}
$$

\section{B.4 Market clearings}

Market balance for each good $i$ stems from the definitions of total domestic supply $S_{i}$ seen from the use and resource sides:

$$
\begin{gathered}
S_{i}=\sum_{j=\mathrm{E}, \mathrm{Q}} \alpha_{i j} Y_{j}+C_{i}+G_{i}+I_{i}+X_{i}, \\
S_{i}=Y_{i}+M_{i} .
\end{gathered}
$$

On the labour market, the unemployment rate is forced at its calibration-year level $A_{u}$ :

$$
u=A_{u}
$$

Market balance is:

$$
(1-u) L=L_{Q}+L_{E}
$$

The wage $w$ adjusts to meet this constraint. This amounts to perfect market specification. ${ }^{7}$

In the non-energy sector, labour consumption and output are conventionally related via labour intensity:

$$
L_{Q}=\lambda_{Q} Y_{Q}
$$

\footnotetext{
${ }^{7}$ We keep $u$ explicit for further explorations with equilibrium unemployment like those of Soummane et al. (2019) on Saudi Arabia.
} 
Labour mobilised in the energy sector $L_{E}$, whose intensity $\lambda_{E}$ derives from China-MAPLE (see Appendix

E) benefits the same productivity gains as non-energy labour $L_{Q}$. Thus:

$$
\phi L_{E}=\lambda_{E} Y_{E}
$$

On the capital market, demands of the two productions balance out capital endowment $K$ :

$$
\sum_{i=E, Q} K_{i}=K
$$

With for the non-energy sector, similarly to labour:

$$
K_{Q}=\kappa_{Q} Y_{Q}
$$

Capital mobilised in the production of the energy good $K_{E}$ is constrained not to contract faster than the depreciation rate $\delta$ :

$$
K_{E, t}=\max \left((1-\delta) K_{E, t-1} ; \kappa_{E} Y_{E}\right)
$$

This constraint was devised for the exploration of the Saudi economy's massive energy sector at annual time steps. It is inoperative in the fast growing context of the Chinese economy modelled at five-year intervals.

\section{B.5 Producer and consumer prices}

Primary factor payments $w$ the wage and $p_{K}$ the price of capital rental are common to both sectors. They adjust according to their market balances.

The price of the $K L$ aggregate $p_{K L}$ is the canonical function ( $K L$ being a CES product of $K$ and $L$ ) of prices $p_{K}$ and $p_{L}$ and of the elasticity of substitution of the two inputs $\sigma_{K L}$ :

$$
p_{K L}=\left(\alpha_{K L}^{\sigma_{K L}}\left(\frac{p_{K}}{\Omega_{K}}\right)^{1-\sigma_{K L}}+\beta_{K L}^{\sigma_{K L}}\left(\frac{w}{\Omega_{L} \phi}\right)^{1-\sigma_{K L}}\right)^{\frac{1}{1-\sigma_{K L}}}
$$


Contrary to $p_{K L}, p_{K L E}$ the price of the $K L E$ aggregate specific to non-energy production cannot be defined as a function of prices $p_{K L}$ and $p_{E Q}$ and of the elasticity of substitution of the two inputs $\sigma_{K L E}$, because exogenously setting $E_{Q}$ in the $K L E$ aggregate truncates the underlying cost-minimisation programme. Consequently, $p_{K L E}$ is rather inferred from the simple accounting equation:

$$
p_{K L E} K L E=p_{K L} K L+p_{E Q} E_{Q}
$$

The producer price of the non-energy good $p_{Y Q}$ is again the canonical CES price of the $K L E$ aggregate and the non-energy input to production $\alpha_{Q Q} Y_{Q}$, to which a constant $a d$ valorem output tax $\tau_{Y_{Q}}$ as well as a constant rent mark-up $\tau_{R_{Q}}$, are added:

$$
p_{Y_{Q}}\left(1-\tau_{Y_{Q}}-\tau_{R_{Q}}\right)=\left(\alpha_{Y}^{\sigma_{Y}} p_{K L E}^{1-\sigma_{Y}}+\beta_{Y}^{\sigma_{Y}} p_{Q Q}^{1-\sigma_{Y}}\right)^{\frac{\rho_{Y}-1}{\rho_{Y}}}
$$

For the energy good, the producer price is simply the sum of production costs:

$$
p_{Y E}=p_{Q E} \alpha_{Q E}+p_{E E} \alpha_{E E}+w \lambda_{E}+p_{K} \kappa_{E}+\tau_{R_{E}} p_{Y E}+\tau_{Y_{E}} p_{Y E}
$$

The import prices of both goods are exogenous: $p_{M Q}$ is constant because the imported non-energy good is the chosen numéraire of the model; and $p_{M E}$ follows an exogenous trajectory inferred from China-MAPLE (Appendix E).

The average supply price of good $i, p_{S i}$, flows from:

$$
p_{S_{i}} S_{i}=p_{Y_{i}} Y_{i}+p_{M_{i}} M_{i}
$$

Turning to purchasers' prices, the price of good $i$ for the production of good $j, p_{i j}$, is equal to the supply price of good $i$ augmented from agent-specific margins $\tau_{M S_{i j}}$ and ad valorem sales taxes $\tau_{S T_{i}}$ :

$$
p_{i j}=p_{S_{i}}\left(1+\tau_{M S_{i j}}\right)\left(1+\tau_{S T_{i}}\right)
$$


The consumer prices of households, public administrations, the investment good and exports are constructed similarly but drop the unnecessary specific margins when energy is not concerned (public consumption, investment), as well as sales taxes as regards exports:

$$
\begin{gathered}
p_{C_{i}}=p_{S_{i}}\left(1+\tau_{M S C_{i}}\right)\left(1+\tau_{S T_{i}}\right) \\
p_{G_{Q}}=p_{S_{Q}}\left(1+\tau_{S T_{i}}\right) \\
p_{I_{Q}}=p_{S_{Q}}\left(1+\tau_{S T_{i}}\right) \\
p_{X_{i}}=p_{S_{i}}\left(1+\tau_{M S X_{i}}\right)
\end{gathered}
$$

In the case of the energy good, the specific margin $\tau_{M S X_{E}}$ endogenously adapts to accommodate the exogenous $p_{X_{E}}$ prescription (see Appendix E). The consumer and import price indexes $C P I$ and $M P I$ are computed as chained indexes, i.e. from one period to the next, according to Fisher's formula:

$$
\begin{gathered}
C P I_{t}=C P I_{t-1} \sqrt{\frac{\sum p_{C i, t} C_{i, t-1}}{\sum p_{C i, t-1} C_{i, t-1}} \frac{\sum p_{C i, t} C_{i, t}}{\sum p_{C i, t-1} C_{i, t}}} \\
M P I_{t}=M P I_{t-1} \sqrt{\frac{\sum p_{M i, t} M_{i, t-1}}{\sum p_{M i, t-1} M_{i, t-1}} \frac{\sum p_{M i, t} M_{i, t}}{\sum p_{M i, t-1} M_{i, t}}}
\end{gathered}
$$




\section{Appendix C. A hybrid energy/economy CHN dataset}

Bringing into consistency energy and national accounting data into a hybrid energy/economy dataset can have significant bearing on energy/economy modelling results (Combet et al., 2014). For that reason, it should be a prerequisite to proper bottom-up/top-down coupling experiments lest BUderived variations apply to flawed cost, budget or trade balance shares. This Appendix summarises our procedure of building a hybrid energy/economy dataset for China and provides the resulting data in the 2-sector format of KLEM. Because this format is shared with that of KLEM-KSA, its exposition is repeated from Soummane et al. (2019), Appendix C. ${ }^{8}$

Our hybridizing procedure consists in crossing national accounting input-output data on energy expenses, energy balance data on energy flows and energy market price data. In case of discrepancy beyond some tolerance level, we prioritise the flow and price data from energy statistics and substitute the resulting expense estimate to the corresponding national accounting data. We adjust all nonenergy elements of the cost structures of energy suppliers to rebalance the uses and resources of energy goods. We aggregate all corrections of uses and resources in a separate sector, which therefore blends actual non-energy activities of energy firms (unaccounted for in supply tables) and mere statistical errors. In the compact format of KLEM we have no choice but to aggregate this correction sector to the non-energy sector.

In the case of China, we performed the procedure on the 42-sector input-output (IO) matrix of 2010 (National Statistics Bureau,2011) with information from the more disaggregated 135-sector IO matrix of 2012 (National Statistics Bureau,2015), the energy balance of 2010 and sets of energy prices from various sources including the China Price Statistics Yearbook 2011, the China Cement Yearbook 2011, the World Economic Operation Report 2011-2012, the China Yearbook 2011, the China Customs

\footnotetext{
8 With kind permission from the authors.
} 
Statistical Yearbook 2011, the Handbook of Brief Energy Data 2016, the International Energy Agency and the ENERDATA Company.

The first step of our data treatment procedure was to disaggregate the 42-sector input-output table (IOT) of year 2010 into 135 sectors, by replicating the sub-sectoral shares of the available 135-sector table of year 2012. We then aggregated the resulting table into 44 sectors (15 of which unchanged from the initial 42-sector matrix) maximising compatibility with the energy-flow disaggregation of the energy balance. Additionally, for lack of direct Chinese sources, we turned to the GTAP database to separate oil and gas extraction into its two components. We also used the energy consumptions of the two GTAP sectors to disaggregate the energy consumptions of 'oil and gas extraction' in the energy balance. We aggregated gas extraction to gas distribution to form one single natural gas supplying activity.

The second step of our data treatment was to cross market price statistics with energy flows to obtain adjusted energy expenses. When lacking price statistics, we constructed price estimates as deviations from the average market price of the relevant energy carrier, taking account of the reported IOT expenses and energy flows. More precisely, if $p_{\text {iot }}$ the price resulting from division of the IOT expense by the energy balance flow is above $p_{a v, \text { iot }}$ the average $p_{\text {iot }}$ across end-users of the same energy carrier, we defined the estimated price $p_{e s t}$ as

$$
p_{\text {est }}=p_{a v, \text { stat }}+\frac{p_{\text {iot }}-p_{a v, i o t}}{p_{\text {max }, i o t}-p_{a v, i o t}} 0.25 p_{a v, \text { stat }}
$$

with $p_{a v, \text { stat }}$ the average of available market price statistics for the same energy carrier and $p_{\text {max }}$ iot the maximum $p_{\text {iot }}$ across end-users of the same energy carrier. Conversely, if $p_{\text {iot }}$ is below $p_{a v \text {,iot }}$ we defined $p_{\text {est }}$ as

$$
p_{e s t}=p_{a v, s t a t}+\frac{p_{a v, i o t}-p_{\text {iot }}}{p_{a v, i o t}-p_{\text {min,iot }}} 0.25 p_{a v, \text { stat }}
$$

with $p_{\text {min,iot }}$ the minimum $p_{\text {iot }}$ across end-users of the same energy carrier. 
The third step of our procedure was to substitute the adjusted energy expenses i.e. the products of the price statistics or estimated prices and of the energy flows, to the original energy expenses of our 44-sector IOT. We then adjusted non-energy inputs into energy sectors by replicating the ratio of nonenergy inputs to energy inputs in the original IOT, taking account of the revised energy-input total. We also homothetically adjusted non-energy inputs into non-energy sectors to maintain the totals of intermediate inputs into all sectors.

The main difficulty in the procedure was the reconciliation of the perimeters and nomenclatures of national accounts and the energy balance. National accounts record commercial flows between economic residents and trade with foreign residents. The energy balance records physical energy flows, their trade, their transformations from primary form to secondary vectors and their final consumption by end-uses. Computing commercial flows from energy balance data therefore required treatment of power and heat autoproductions (which only appear through primary energy consumptions in national accounts) and of international bunkers (a geographic notion orthogonal to the administrative definition of the perimeter of national accounts). It also required disaggregating the road transport end-use between households' direct consumptions of vehicle fuels and those of firms, among which transport service suppliers. ${ }^{9}$

\footnotetext{
${ }^{9}$ Combet et al. (2014) and Le Treut (2017) detail similar hybridisation in the case of France. The particulars of our procedure are available upon request.
} 
Figure C.1 Hybrid dataset of 2010 China in KLEM-CHN 2-sector format

\begin{tabular}{|c|c|c|c|c|c|c|c|}
\hline IOT, Billion RMB & Prod. Q & Prod. E & C & G & 1 & $x$ & \\
\hline Q uses & 70477 & 2140 & 13717 & 5197 & 18367 & 10934 & 120832 \\
\hline E uses & 6167 & 3605 & 758 & 0 & 0 & 267 & 10797 \\
\hline L net & 17543 & 919 & & & & & \\
\hline $\mathrm{L}$ taxes & 448 & 36 & & & & & \\
\hline $\mathrm{Y}$ taxes & 4115 & 678 & & & & & \\
\hline K & 13673 & 1273 & & & & & \\
\hline $\mathrm{R}$ & 26 & 15 & & & & & \\
\hline M & 8015 & 1890 & & & & & \\
\hline SM use in $Q$ & 0 & 2027 & & & & & \\
\hline SM use in $E$ & 0 & -2302 & & & & & \\
\hline SM use in $C$ & 0 & 154 & & & & & \\
\hline SM use in $\mathrm{G}$ & 0 & 0 & & & & & \\
\hline SM use in I & 0 & 0 & & & & & \\
\hline SM use in $X$ & 0 & 121 & & & & & \\
\hline \multirow[t]{2}{*}{ Sales T } & 367 & 240 & & & & & \\
\hline & 120832 & 10797 & & & & & \\
\hline
\end{tabular}

\begin{tabular}{|c|c|c|c|c|c|c|c|}
\hline E flows, Mtce & Prod. Q & Prod. E & C & G & 1 & $\mathrm{x}$ & \\
\hline E uses & 2028 & 2954 & 297 & 0 & 0 & 74 & 5353 \\
\hline Imports & & 566 & & & & & \\
\hline Output & & 4787 & & & & & \\
\hline
\end{tabular}

\begin{tabular}{|c|c|c|c|c|c|c|}
\hline E prices, RMB/tce & Prod. Q & Prod. E & $\mathrm{C}$ & $\mathrm{G}$ & I & $x$ \\
\hline E uses & 3040 & 1220 & 2548 & - & - & 3613 \\
\hline Imports & & 3338 & & & & \\
\hline
\end{tabular}

"IOT" stands for Input-output table, "E" for Energy. Totals may not add up due to rounding.

The resulting IOT in billion renminbi (RMB) and satellite account of energy flows in million tons of coalequivalent (Mtce) organise as follows (Figure C.1). In column, resources of the non-energy good $Q$ and the energy good $E$ build up from intermediate consumptions ( $Q$ or $E$ uses), labour costs $L$, capital costs $K$, output taxes ' $Y$ taxes', the rent on natural resources $R$, imports $M$, specific margins $S M$ and net-ofsubsidies 'Sales taxes'. Specific margins on energy uses are calibrated as the difference between sales at prices inferred from the energy-flow account and sales at the average resource price $p_{S_{E}}$ (an average of output and import prices, see Appendix B) augmented by net sales taxes. They allow modelling agent-specific prices (see Equations 28 to 32 of Appendix B) i.e. overcoming undesirable consequences 
of the uniform pricing standard, as Combet et al. (2014) demonstrated. All specific margins on Q uses are nil in the absence of any satellite account of physical flows that would point at agent-specific pricing. In line, $\mathrm{Q}$ and $\mathrm{E}$ are used as inputs into productions, as consumption goods for households $(\mathrm{C})$ and public administrations (G), as investment goods (I) or as exports (X). In the energy-flow account, the energy consumption of the non-energy sector ('E uses' in 'Prod $Q$ ') aggregates total final energy consumption net of households' consumption C, which proceeds from residential energy consumptions and a share of refined products consumptions for transportation purposes. The energy consumption of the energy sector ('E uses' in 'Prod E') aggregates commercial flows between energy firms.

By national accounting convention, the consumption of energy goods by public administrations is nil. ${ }^{10}$ Investment of energy goods is nil as well, once stock variations have been cancelled out by adjusting output. Exports $(\mathrm{X})$ and imports $(\mathrm{M})$ are close matches to their energy balance counterparts. The price of each energy use is specific thanks to specific margins SM (see above).

According to our hybrid dataset (Figure C.1), in 2010 the Chinese energy sector represents $19.1 \%$ of total imports and $7.5 \%$ of value-added, $5.5 \%$ of the output cost of non-energy supply and $5.2 \%$ of households' consumption budget. Before hybridisation, the corresponding indicators were $1.8 \%$ of total imports, $8.3 \%$ of value-added, $5.7 \%$ of the output cost of non-energy supply and $3.6 \%$ of households' consumption budget.

\footnotetext{
${ }^{10}$ The consumption of public institutions is registered as intermediate consumption by the public services sector, which is aggregated to the non-energy good in our 2-sector dataset.
} 


\section{Appendix D. Calibration of KLEM-CHN capital dynamics}

Capital accumulation of KLEM-CHN follows standard perpetual inventory specifications but with explicit accounting of year-to-year variations between the 5-year time steps of the model.

\section{D.1 Calibration of the base-year capital stock}

Our original hybrid energy/economy calibration data (see Appendix C) lacks some estimate of the initial capital stock. Turning to statistics on such matter risks raising consistency issues with 2010 investment and the accumulation rule, leading to capital stock trajectories with trends diverging from efficient labour supply and thus to artificial relative abundance or scarcity of the capital stock-with ultimate impacts on the costs of more capital-intensive trajectories. Following Soummane et al. (2019), we rather define $K_{0}$ the base-year capital stock of KLEM-CHN as:

$$
K_{0}=I_{Q, 0} \frac{1}{\delta+g_{1}}
$$

with $\delta$ the depreciation rate dividing the 2010 investment volume $I_{Q, 0}$ to account for the amount of capital $(\delta K)$ that will be retired at the end of 2010 and must therefore be replaced by $I_{Q, 0}$; and $g_{1}$ the potential growth rate between 2010 and 2011, resulting from the combined growth of labour supply and labour productivity i.e. the growth of efficient labour. Dividing $I_{Q, 0}$ by $g_{1}$ warrants that the 2011 capital stock resulting from 2010 investment grows apace with efficient labour.

\section{D.2 Full-horizon calibration of investment rate dynamics}

Starting from $K_{0}$ and $I_{Q, 0}$, the standard accumulation rule defines the trajectory of the capital stock as

$$
K_{y+1}=(1-\delta) K_{y}+I_{Q, y}
$$

with time subscripts $y$ conveying that we keep track of this trajectory in yearly time steps in-between each of the 5-year intervals of KLEM-CHN. Our choice of a Johansen closure means to reflect the 
strongly planned nature of the Chinese economy. Similar to the savings rate dynamics under neoclassical closure, it requires some assumption on the investment rate dynamics. We calibrate these dynamics in such a manner that the capital stock grows at the same pace as efficient labour when (real) GDP also does. Notwithstanding the small discrepancies between the investment price index and the GDP price index, the year- $y$ investment effort (share of GDP invested) $s_{I, y}$ should thus follow:

$$
s_{I, y}=s_{I, 0}\left(\frac{1+g_{y+1}}{1+g_{y}}-(1-\delta)\right) \frac{K_{0}}{I_{\mathrm{Q}, 0}}
$$

With $g_{y}$ the potential growth rate between year 0 and year $y$-defined as the growth rate of efficient labour $\frac{\phi L_{y}}{L_{0}}$ in KLEM notations. This equation holds at each 5 -year interval as well to define the investment effort effectively enforced in KLEM-CHN.

\section{D.3 5-year dynamics of the capital stock}

KLEM-CHN computes capital stocks in 5-year time steps $t$ as

$$
K_{t+1}=(1-\delta)^{5} K_{t}+A_{t} I_{t}
$$

where $A_{t}$ is a multiplier of $I_{t}$ that means to approximate the effect of investment growth between $t$ and $t+1$ on $K_{t+1}$, duly accounting for depreciation. We compute $A_{t}$ in the case when potential growth realises, where it is analytically tractable as a function of the depreciation rate $\delta$ and of potential growth rates $g$ :

$$
A_{t}=\sum_{i=0}^{4}(1-\delta)^{4-i} \frac{g_{y+i+1}+\delta}{g_{y+1}+\delta}
$$

where year $y$ is time period $t$ and years $y+1$ to $y+3$ are the 3 years between period $t$ and period $t+1$ 


\section{Appendix E. KLEM-CHN parameter trajectories inferred from China-MAPLE}

KLEM-CHN parameter trajectories inferred from China-MAPLE cover 5 energy volumes, 2 prices of energy trade, 3 margins on energy sales and one deviation from base year values identically affecting the calibrated non-energy, labour and capital intensities of energy supply $\left(\alpha_{Q E}, \lambda_{E}\right.$ and $\kappa_{E}$ in KLEMCHN notations).

The 5 energy volumes are the 4 non-nil uses of energy of KLEM-CHN's satellite account of energy flows (see Appendix C)-inputs to transformation by energy firms $E_{E}$, final consumptions of non-energy firms $E_{Q}$, final consumptions of households $C_{E}$ and exports $X_{E}$-as well as energy imports $M_{E}$. Together, these five flows define energy 'output' $Y_{E}$ in the input-output sense of KLEM-CHN, as the difference between the sum of uses and imports $E_{E}+E_{Q}+C_{E}+X_{E}-M_{E}$. For a given scenario, we compute the 5 flows at every five-year interval in China-MAPLE following a procedure of nomenclature and perimeter harmonization very similar to that producing KLEM-CHN's hybrid calibration data. One significant difference is that China-MAPLE only tracks net imports of energy goods, which we must disaggregate between gross imports and exports. We do so by assuming that, for each energy good, the two trade flows evolve inversely from their base-year (2010) levels, which we know from the Chinese energy balance.

We also easily compute at every five-year interval $p_{X E}$ and $p_{M E}$ the prices of aggregate energy exports and imports as the weighted averages of the prices of all exported and imported energy commodities in China-MAPLE.

The margins on domestic energy sales $\tau_{M S_{E E}}, \tau_{M S_{E Q}}$ and $\tau_{M S C_{E}}$ and $\delta_{E}$ the scalar to base-year values of the 3 non-energy intensities of energy supply (not an explicit KLEM-CHN parameter) flow from the complex procedure described at the end of Section 3.4. Let us illustrate this procedure. Keeping on using KLEM-CHN notations (see Appendix B ) and indexing calibration (2010) values with 0 subscripts, 
at each time $t$ of China-MAPLE trajectory, our first step is to compute a 'KLEM-BU' energy output price building on constant non-energy costs and taxes, as:

$$
p_{Y E, t}^{B U}=\frac{p_{Q E, 0} \alpha_{Q E, 0}+p_{E E, t} \alpha_{E E, t}+w_{0} \lambda_{E, 0}+p_{K, 0} \kappa_{E, 0}}{1-\tau_{R_{E}, 0} p_{Y E, t}^{B U}-\tau_{Y_{E}, 0} p_{Y E, t}^{B U}}
$$

which is simply the sum of unit input costs into energy production, Equation 26 of KLEM. The only elements of this cost structure evolving through time are the energy intensity of energy supply (transformation) $\alpha_{E E}$ and its market price $p_{E E}$-for the sake of readability we drop time indexes henceforth. Both are derived from China-MAPLE at each time step, $\alpha_{E E}$ as the ratio of the total energy input into energy supply $E_{E}$ and of energy 'output' in the input-output sense of KLEM-CHN $Y_{E}$; $p_{E E}$ as the weighted average of the prices of the energy flows aggregating in $E_{E}$.

Our second step is to average $p_{Y E}^{B U}$ and $p_{M E}$ the China-MAPLE-derived price of energy imports at same time $t$, into the 'KLEM-BU' supply price $p_{S E}^{B U}$. We do this taking account of what China-MAPLE indicates on the aggregate balance of imports and domestic output into supply at time $t$, following Equation (15) of KLEM-CHN:

$$
p_{S E}^{B U}=\frac{Y_{E}}{Y_{E}+M_{E}} p_{Y E}^{B U}+\frac{M_{E}}{Y_{E}+M_{E}} p_{M E}
$$

Still following KLEM-CHN equations, we then build 'KLEM-BU' domestic energy market prices as:

$$
\begin{gathered}
\forall j \in\{Q, E\} \quad p_{E j}^{B U}=p_{S E}^{B U}\left(1+\tau_{M S_{E j}, 0}\right)\left(1+\tau_{S T_{E}, 0}\right), \\
p_{C_{E}}^{B U}=p_{S E}^{B U}\left(1+\tau_{M S C_{E}, 0}\right)\left(1+\tau_{S T_{E}, 0}\right)
\end{gathered}
$$

as well as the 'KLEM-BU' energy export price:

$$
p_{X_{E}}^{B U}=p_{S E}^{B U}\left(1+\tau_{M S X_{E}, 0}\right)
$$

Our third step is to identify which of these four 'KLEM-BU' prices is the closest from the corresponding China-MAPLE prices including the very $p_{E E}$ governing their trajectories, and to compute the value of $\delta_{E}$ bridging the gap between this KLEM-BU price and its China-MAPLE counterpart. We renew the 
comparison at every time period. Let us assume that at some time period $t$ the gap is smallest between $p_{E Q}^{B U}$ and the average price of final energy consumption by firms inferred from China-MAPLE $p_{E Q}^{M A P L E}$, then $\delta_{E}$ at time $t$ is the solution to:

$$
\begin{gathered}
\frac{Y_{E}}{Y_{E}+M_{E}} \frac{\left(1+\delta_{E}\right)\left(p_{Q E, 0} \alpha_{Q E, 0}+w_{0} \lambda_{E, 0}+p_{K, 0} \kappa_{E, 0}\right)+p_{E E} \alpha_{E E}}{1-\tau_{R_{E}, 0}-\tau_{Y_{E}, 0}}\left(1+\tau_{M S_{E Q}, 0}\right)\left(1+\tau_{S T_{E}, 0}\right) \\
+\frac{M_{E}}{Y_{E}+M_{E}} p_{M E}\left(1+\tau_{M S_{E Q}, 0}\right)\left(1+\tau_{S T_{E}, 0}\right)=p_{E Q}^{M A P L E}
\end{gathered}
$$

where the values without 0 subscript $Y_{E}, M_{E}, p_{E E}$ and $\alpha_{E E}$ are all inferred from time $t$ China-MAPLE results similar to $p_{E Q}^{M A P L E}$.

The last stage of our procedure is to factor in the resulting $\delta_{E}$ in updated 'KLEM-BU' prices and to compute what adjustment of the specific margins allows aligning these updated 'KLEM-BU' prices on their China-MAPLE counterparts.

\section{Appendix F. Scenario assumptions}

\begin{tabular}{|c|c|c|}
\hline Sector & BAU & DDP \\
\hline \multirow[t]{5}{*}{$\begin{array}{l}\text { Power } \\
\text { generation }\end{array}$} & $\begin{array}{l}\text { Share of coal-fuelled plants declines to } 50 \% \text { by } \\
2020 \text { and remains below that cap. }\end{array}$ & $\begin{array}{l}\text { Share of coal-fuelled plants declines to } 50 \% \text { by } \\
2020 \text {. Ban on new coal plant after } 2020 \text { (with or } \\
\text { without CCS). }\end{array}$ \\
\hline & $\begin{array}{l}\text { Nuclear power capacity reaches } 58 \mathrm{GW} \text { in } 2020 \\
\text { then follows past development trends to } 200 \mathrm{GW} \\
\text { in } 2050 \text {. }\end{array}$ & $\begin{array}{l}\text { Nuclear power capacity reaches } 58 \mathrm{GW} \text { in } 2020 \\
\text { then accelerates its development to reach } 410 \mathrm{GW} \\
\text { by } 2050 \text {. }\end{array}$ \\
\hline & Gas-fired capacity reaches 116 GW in 2020. & Gas-fired capacity reaches 116 GW in 2020. \\
\hline & $\begin{array}{l}\text { Hydropower capacity reaches } 380 \mathrm{GW} \text { in } 2020 \\
\text { then reaches its resource-endowment limit of } \\
450 \mathrm{GW} \text { in } 2040 .\end{array}$ & $\begin{array}{l}\text { Hydropower capacity reaches } 380 \mathrm{GW} \text { in } 2020 \\
\text { then reaches its resource-endowment limit of } \\
450 \mathrm{GW} \text { in } 2040 \text {. }\end{array}$ \\
\hline & $\begin{array}{l}\text { Wind and solar power capacity reaches } 300 \mathrm{GW} \text { in } \\
2020 \text { then grows moderately to at least } 700 \mathrm{GW} \text { in } \\
2050 \text {. }\end{array}$ & $\begin{array}{l}\text { Wind and solar power capacity reaches } 300 \mathrm{GW} \text { in } \\
2020 \text { then grows rapidly to at least } 2800 \mathrm{GW} \text { in } \\
2050 \text {. }\end{array}$ \\
\hline \multirow[t]{2}{*}{ Industry } & Small-scale industrial plants remain in activity. & $\begin{array}{l}\text { Small-scale industrial plants are phased out by } \\
2020 \text { and replaced by more efficient large-scale } \\
\text { plants. }\end{array}$ \\
\hline & $\begin{array}{l}\text { Efficient technologies penetrate following the } \\
\text { 13th 5-year plan up to } 2020 \text { then keep } \\
\text { penetrating at similar rates up to } 2050 \text {. }\end{array}$ & $\begin{array}{l}\text { Efficient technologies penetrate following the } \\
\text { 13th 5-year plan up to } 2020 \text { then accelerate. In } \\
2050 \text {, only the most efficient technologies are } \\
\text { invested in. }\end{array}$ \\
\hline
\end{tabular}

\section{Table F.1 Scenario constraints}




\begin{tabular}{|c|c|c|}
\hline \multirow[t]{4}{*}{ Transport } & $\begin{array}{l}\text { Total number of electric and hybrid vehicles } \\
\text { reaches five million units in } 2020 \text {. }\end{array}$ & $\begin{array}{l}\text { Total number of electric and hybrid vehicles } \\
\text { reaches five million units in } 2020 \text {. }\end{array}$ \\
\hline & $\begin{array}{l}\text { Fuel efficiency improves through tightening } \\
\text { standards. }\end{array}$ & $\begin{array}{l}\text { Fuel efficiency improves through tightening } \\
\text { standards. }\end{array}$ \\
\hline & $\begin{array}{l}\text { After } 2020 \text {, electric and hybrid vehicle sales follow } \\
\text { recent historical trend but decline to average } \\
\text { vehicle sales growth after } 2025\end{array}$ & $\begin{array}{l}\text { After } 2020 \text {, sales of internal-combustion-engine } \\
\text { light-duty vehicles are capped. Share of electric } \\
\text { and hybrid vehicles at least } 80 \% \text { by } 2050 \text {. }\end{array}$ \\
\hline & & $\begin{array}{l}\text { After } 2020 \text {, sales of internal-combustion-engine } \\
\text { buses and trucks are capped. Shares of electric \& } \\
\text { hybrid buses and trucks at least } 60 \% \text { and } 30 \% \text { by } \\
2050 \text {. }\end{array}$ \\
\hline \multirow[t]{4}{*}{ Buildings } & $\begin{array}{l}\text { Energy efficiency of heat } \& \text { power plants increases } \\
0.49 \% \text { per year. }\end{array}$ & $\begin{array}{l}\text { Energy efficiency of heat \& power plants increases } \\
0.49 \% \text { per year. Gas heating plants and electric } \\
\text { heaters provide at least } 90 \% \text { of heating service by } \\
2050 \text {. }\end{array}$ \\
\hline & $\begin{array}{l}\text { LED provide at least } 15 \% \text { of lighting services by } \\
2050 \text {. }\end{array}$ & $\begin{array}{l}\text { LED provide at least } 20 \% \text { of lighting services by } \\
2050 \text {. }\end{array}$ \\
\hline & $\begin{array}{l}\text { Energy efficiency of cooking and water heating } \\
\text { increases at } 0.49 \% \text { per year. }\end{array}$ & $\begin{array}{l}\text { Energy efficiency of cooking and water heating } \\
\text { increases at } 0.49 \% \text { every year. Forced shift to } \\
\text { electricity and gas equipment, phase-out of coal } \\
\text { consumption in urban areas. }\end{array}$ \\
\hline & & $\begin{array}{l}\text { Performance of residential insulation improved by } \\
80 \% \text { by } 2050 \text {. }\end{array}$ \\
\hline
\end{tabular}

All scenario constraints act as lower-bound or upper-bound constraints to the energy system cost-minimisation performed by China-MAPLE.

\section{References}

Abrell J, Rausch S (2016) Cross-country electricity trade, renewable energy and European transmission infrastructure policy. J Environ Econ Manage 79:87-113

Anderson S T, Parry, I W H, Sallee J M et al (2011) Automobile Fuel Economy Standards: Impacts, Efficiency, and Alternatives. Rev Environ Econ Policy5:89-108

Aziz J, and Li X (2008) China's changing trade elasticities. China World Econ 16(3):1-21. doi 10.1111/j.1749-124X.2008.00111.x

Bataille C, Waisman H, Briand Y et al (2020) Net-zero deep decarbonization pathways in Latin America: Challenges and opportunities. Energy Strategy Rev 30: 100510. DOI 10.1016/J.ESR.2020.100510

Bataille C, Melton N (2017) Energy efficiency and economic growth: A retrospective CGE analysis for Canada from 2002 to 2012. Energy Econ 64:118-130. DOI 10.1016/j.eneco.2017.03.008

Bretschger Lucas, and Karen Pittel (2020) Twenty Key Challenges in Environmental and Resource Economics. Environ Resour Econ (Dordr) 77(4):725-50.

Chen W (2005) The costs of mitigating carbon emissions in China: findings from China MARKAL-MACRO modeling. Energy Policy 33:885-896 
Chen W, Wu Z, He J et al (2007) Carbon emission control strategies for China: A comparative study with partial and general equilibrium versions of the China MARKAL model. Energy 32:59-72. DOI 10.1016/J.ENERGY.2006.01.018

Combet E, Ghersi F, Lefevre J, Le Treut G (2014) Construction of hybrid Input-Output tables for E3 CGE model calibration and consequences on energy policy analysis. GTAP resource 4524, Global trade Analysis Program, Purdue University, https://www.gtap.agecon.purdue.edu/resources/download/6988.pdf. Cited 14 Dec 2020

Cohen S M, Caron J (2018) The economic impacts of high wind penetration scenarios in the United States. Energy Econ 76:558-573. DOI 10.1016/j.eneco.2018.10.023

Dai H, Mischke P, Xie X et al (2016a) Closing the gap? Top-down versus bottom-up projections of China's regional energy use and CO2 emissions. Appl Energy 162:1355-1373. DOI 10.1016/j.apenergy.2015.06.069

Dai H, Xie X, Xie Y et al (2016b) Green growth: The economic impacts of large-scale renewable energy development in China. Appl Energy 162:435-449. DOI 10.1016/j.apenergy.2015.10.049

Dai $\mathrm{H}, \mathrm{Xie} \mathrm{Y}$, Liu J et al (2018) Aligning renewable energy targets with carbon emissions trading to achieve China's INDCs: A general equilibrium assessment. Renew Sust Energ Rev 82:4121-4131. DOI 10.1016/j.rser.2017.10.061

Duan H-B, Zhu L, Fan Y (2014) Optimal carbon taxes in carbon-constrained China: A logistic-induced energy economic hybrid model. Energy 69:345-356. DOI 10.1016/j.energy.2014.03.022

European Environment Agency (2013) Adaptation in Europe: addressing risks and opportunities from climate change in the context of socio-economic developments. Publ. Off. of the European Union, Luxembourg.

Feng S, and K Zhang (2018) Fuel-factor nesting structures in CGE models of China. Energy Econ 75:274284, DOI .

Fortes P, Pereira R, Pereira A et al (2014). Integrated technological-economic modeling platform for energy and climate policy analysis. Energy 73:716-730. DOI 10.1016/J.ENERGY.2014.06.075

Fortes P, Simões S, Seixas J, Van Regemorter D, Ferreira F (2013) Top-down and bottom-up modelling to support low-carbon scenarios: climate policy implications. Clim Policy 13(3):285-304, DOI 10.1080/14693062.2013.768919

Fujimori S, Oshiro K, Shiraki H, Hasegawa T (2019) Energy transformation cost for the Japanese midcentury strategy. Nat Commun 10. DOI 10.1038/s41467-019-12730-4

Ghersi F (2015) Hybrid Bottom-up/Top-down Energy and Economy Outlooks: A Review of IMACLIM-S Experiments. Front Environ Sci 3:74. DOI 10.3389/fenvs.2015.00074

Grubler A, Wilson C, Bento $\mathrm{N}$ et al (2018) A low energy demand scenario for meeting the $1.5^{\circ} \mathrm{C}$ target and sustainable development goals without negative emission technologies. Nat Energy 3: 515-527.

Gupta D, Ghersi F, Vishwanathan S S et al (2019). Achieving sustainable development in India along low carbon pathways: Macroeconomic assessment. World Dev123: 104623.. 
Gupta D, Ghersi F, Vishwanathan S S et al (2020). Macroeconomic assessment of India's development and mitigation pathways. Clim Policy 20(7): 779-799.

Helgesen $\mathrm{PI}$, Lind A, Ivanova $\mathrm{O}$ et al (2018) Using a hybrid hard-linked model to analyze reduced climate gas emissions from transport. Energy 156, 196-212. DOI 10.1016/j.energy.2018.05.005

Helgesen P.I, Tomasgard, A (2018) From linking to integration of energy system models and computational general equilibrium models - Effects on equilibria and convergence. Energy 159:12181233. DOI 10.1016/j.energy.2018.06.146

Hoffman K.C, Jorgenson D.W, 1977. Economic and Technological Models for Evaluation of Energy Policy. BELL J ECON 8:444. DOI 10.2307/3003296

Hourcade J-C, Jaccard M, Bataille $C$ et al (2006) Hybrid modeling: new answers to old challenges introduction to the special issue of" the energy journal". Energy J 1:11.

ILO (2014) World of Work Report 2014: Developing with jobs. International Labour Office.

Intergovernmental Panel on Climate Change, Edenhofer, O. (Eds.) (2014) Climate change 2014: mitigation of climate change: Working Group III contribution to the Fifth Assessment Report of the Intergovernmental Panel on Climate Change. Cambridge University Press, New York, NY.

Jacobsson S, Lauber V (2006) The politics and policy of energy system transformation--explaining the German diffusion of renewable energy technology. Energy Policy 34:256-276

Johansen L (1960) A Multi-sector Study of Economic Growth - Leif Johansen - Google Livres. NorthHolland Publishing Company.

Krook-Riekkola A, Berg C, Ahlgren EO et al (2017) Challenges in top-down and bottom-up soft-linking: Lessons from linking a Swedish energy system model with a CGE model. Energy 141:803-817. DOI 10.1016/j.energy.2017.09.107

Labriet M, Drouet L, Vielle M et al (2015) Assessment of the Effectiveness of Global Climate Policies Using Coupled Bottom-Up and Top-Down Models. SSRN Electro J. DOI 10.2139/ssrn.2580216

Lefèvre J (2016) Hybridization challenges in energy-economy integrated models and representation of the low carbon transition - An application to the Brazilian case. Université Paris-Saclay - Ecole doctorale ABIES.

https://hal.archives-ouvertes.fr/tel-01707559Le Treut G, Combet E, Lefèvre J, Teixeira A, Baudin A (2019) IMACLIM-Country platform: a country-scale computable general equilibrium model. DOI 10.5281/ZENODO.3403961

Liu Y, Lu Y (2015) The Economic impact of different carbon tax revenue recycling schemes in China: A model-based scenario analysis. Appl Energy 141:96-105. DOI 10.1016/j.apenergy.2014.12.032

Loulou R, Goldstein G, Kanudia A, Lehtila A, \& Remne U (2016) Documentation for the TIMES modelPart 1. https://iea-etsap.org/docs/Documentation_for_the_TIMES_Model-Part-I_July-2016.pdf. Cited 14 Dec 2020

Lu Yingying, and David I. Stern. (2016) Substitutability and the Cost of Climate Mitigation Policy. Environ Resour Econ (Dordr) 64(1):81-107. . Cited 14 Dec 2020 
Manne AS (1977) ETA-MACRO: A model of energy-economy interactions. NASA STI/Recon Technical Report N 78: 26612.

Martinsen T (2011) Introducing technology learning for energy technologies in a national CGE model through soft links to global and national energy models. Energy Policy 39:3327-3336. DOI 10.1016/J.ENPOL.2011.03.025

Mu Y, Wang C, Cai W (2018) The economic impact of China's INDC: Distinguishing the roles of the renewable energy quota and the carbon market. Renew Sust Energ Rev 81: 2955-2966. DOI 10.1016/j.rser.2017.06.105

National Statistics Bureau (2011) China Input-output Tables 2010, Available at: http://data.stats.gov.cn//files/html/quickSearch/trcc/trcc05.html. Cited 14 Dec 2020

National Statistics Bureau (2015) China Input-output Tables 2012, China statistics press, Beijing.

Okagawa A and Ban K (2008) 'Estimation of substitution elasticities for CGE models', Discussion Papers in Economics, pp. 1-18. Available at: http://118.151.132.36/ip/workshop/080225/03 report5 Okagawa.pdf. Cited 14 Dec 2020

Proenca SA, Aubyn MS (2009) A hybrid Top-down/Bottom-up model for energy policy analysis in a small open economy-the Portuguese case. Tech. rep. Discussion paper.

Rausch S, Mowers M (2014) Distributional and efficiency impacts of clean and renewable energy standards for electricity. Resour Energy Econ 36: 556-585. DOI 10.1016/j.reseneeco.2013.09.001

Remme U. and BlesI M (2006). "Documentation of the TIMES-MACRO model". Energy Technology Systems Analysis Programme (ETSAP). Downloaded from: Cited 14 Dec 2020

Rogelj J, Luderer G, Pietzcker R.C et al (2015) Energy system transformations for limiting end-of-century warming to below $1.5^{\circ} \mathrm{C}$. Nat Clim Chang 5: 519-527. DOI 10.1038/nclimate2572

Shen K. and Whalley J (2013) "Capital-labor-energy substitution in nested CES production functions for China." NBER Working Paper 19104, NBER Work Pap Ser , Cambridge, MA.

Soummane S, Ghersi F, Lefèvre J (2019) Macroeconomic pathways of the Saudi economy: The challenge of global mitigation action versus the opportunity of national energy reforms. Energy Policy 130:263-282. doi 10.1016/j.enpol.2019.03.062

Stern N, Calderon F (2014) Better growth, better climate: The new climate economy report. The Global Commission on the Economy and Climate, New York

Su X, Zhou W, Nakagami K et al (2012) "Capital stock-labor-energy substitution and production efficiency study for China." Energy Econ 34 1208-1213. http://dx.doi.org/10.1016/j.eneco.2011.11.002DOI

United Nations Development Programme (2015) World population prospects: The 2015 revision. United Nations Econ Soc Aff 33:1-66

Van der Werf E (2008) Production functions for climate policy modeling: An empirical analysis. Energy Econ 30(6):2964-2979. doi 10.1016/j.eneco.2008.05.008 
Waisman H, Bataille C, Winkler $\mathrm{H}$ et al (2019) A pathway design framework for national low greenhouse gas emission development strategies. Nat Clim Chang 9: 261-268. DOI 10.1038/s41558-019-0442-8

Wang X, Teng F, Yang X et al (2017) Assessing the role of electricity storage in China's high renewable energy penetration future. Enrgy Proced 105:4084-4089. DOI 10.1016/j.egypro.2017.03.865

Wene C (1996) Energy-economy analysis: Linking the macroeconomic and systems engineering approaches. Energy 21:809-824. DOI 10.1016/0360-5442(96)00017-5

Wu Y-H et al (2019) 'Sectoral energy efficiency improvements in Taiwan: Evaluations using a hybrid of top-down and bottom-up models', Energy Policy. Elsevier 132:1241-1255. DOI 10.1016/J.ENPOL.2019.06.043Zha D, and Zhou D (2014) The elasticity of substitution and the way of nesting CES production function with emphasis on energy input. Appl Energ 130:793-798. DOI 10.1016/j.apenergy.2014.01.093.

Zhang D, Rausch S, Karplus V.J, Zhang X (2013) Quantifying regional economic impacts of CO2 intensity targets in China. Energy Econ 40: 687-701. DOI 10.1016/j.eneco.2013.08.018

Zhang J, Wu G, Zhan J (2004) The estimation of China's provincial capital stock: 1952-2000. Econ Res J 10:35-44 (in Chinese)

Zhang Y, Shi X, Qian X, Chen S, Nie R(2021). Macroeconomic effect of energy transition to carbon neutrality: Evidence from China's coal capacity cut policy. Energy Policy 155, 112374. DOI 10.1016/j.enpol.2021.112374 